\title{
The atmospheric composition and structure of Jupiter and Saturn from ISO observations: a preliminary review
}

\author{
Th. Encrenaz ${ }^{\mathrm{a}, *}$, P. Drossart ${ }^{\mathrm{a}}$, H. Feuchtgruber ${ }^{\mathrm{b}}$, E. Lellouch ${ }^{\mathrm{a}}$, B. Bézard ${ }^{\mathrm{a}}$, \\ T. Fouchet ${ }^{\mathrm{a}}$, S.K. Atreya ${ }^{\mathrm{c}}$ \\ ${ }^{a}$ DESPA, Observatoire de Paris, F-92195, Meudon, France \\ ${ }^{\mathrm{b}}$ Max-Planck-Institut für Extraterrestrische Physik, D-85748, Garching, Germany \\ ${ }^{\mathrm{c}}$ The University of Michigan, Ann Arbor, MI, 48109-2143, USA
}

Received 29 October 1998; accepted 30 December 1998

\begin{abstract}
Infrared spectra of Jupiter and Saturn have been recorded with the two spectrometers of the Infrared Space Observatory (ISO) in 1995-1998, in the 2.3-180 $\mu \mathrm{m}$ range. Both the grating modes $(R=150-2000)$ and the Fabry-Pérot modes $(R=8000-$ $30,000)$ of the two instruments were used. The main results of these observations are (1) the detection of water vapour in the deep troposphere of Saturn; (2) the detection of new hydrocarbons $\left(\mathrm{CH}_{3} \mathrm{C}_{2} \mathrm{H}, \mathrm{C}_{4} \mathrm{H}_{2}, \mathrm{C}_{6} \mathrm{H}_{6}, \mathrm{CH}_{3}\right)$ in Saturn's stratosphere; (3) the detection of water vapour and carbon dioxide in the stratospheres of Jupiter and Saturn; (4) a new determination of the $\mathrm{D} /$ $\mathrm{H}$ ratio from the detection of HD rotational lines. The origin of the external oxygen source on Jupiter and Saturn (also found in the other giant planets and Titan in comparable amounts) may be either interplanetary (micrometeoritic flux) or local (rings and/or satellites). The $\mathrm{D} / \mathrm{H}$ determination in Jupiter, comparable to Saturn's result, is in agreement with the recent measurement by the Galileo probe (Mahaffy, P.R., Donahue, T.M., Atreya, S.K., Owen, T.C., Niemann, H.B., 1998. Galileo probe measurements of $\mathrm{D} / \mathrm{H}$ and ${ }^{3} \mathrm{He} /{ }^{4} \mathrm{He}$ in Jupiters atmosphere. Space Science Rev. 84 251-263); the D/H values on Uranus and Neptune are significantly higher, as expected from current models of planetary formation. (C) 1999 Elsevier Science Ltd. All rights reserved.
\end{abstract}

\section{Introduction}

Infrared spectroscopy with ISO (Infrared Space Observatory) has made a significant contribution to our knowledge of the atmospheres of Jupiter and Saturn. Launched in November 1995, the heliumcooled satellite operated until April 1998, and was thus able to observe Jupiter at the same time as the Galileo mission. With its two spectrometers, SWS (Short Wavelength Spectrometer) and LWS (Long Wavelength Spectrometer) ISO was able to explore the entire spectrum of Jupiter and Saturn between 2.3 and $180 \mu \mathrm{m}$. Several important results have been obtained from these data: a new determination of the $\mathrm{D} / \mathrm{H}$ ratio; the detection of $\mathrm{H}_{2} \mathrm{O}$ and $\mathrm{CO}_{2}$ in the strato-

\footnotetext{
* Corresponding author.
}

spheres of the two planets; the detection of new hydrocarbons in the stratosphere of Saturn $\left(\mathrm{CH}_{3} \mathrm{C}_{2} \mathrm{H}, \mathrm{C}_{4} \mathrm{H}_{2}\right.$, $\mathrm{C}_{6} \mathrm{H}_{6}, \mathrm{CH}_{3}$ ); the detection of $\mathrm{H}_{2} \mathrm{O}$ in the deep troposphere of Saturn. In addition, information has been retrieved on the thermal structure of Jupiter and Saturn, and on the vertical distribution of their atmospheric constituents. These results have been obtained largely from the SWS spectra below $45 \mu \mathrm{m}$; some of the LWS data are still being reduced.

On the other hand, the Galileo probe and orbiter observations have provided the closest view ever obtained from a giant planet (Young et al., 1996; Young, 1998), and considerable amounts of orbiter data are still being produced. Whereas the Galileo probe measured in situ the atmospheric composition and structure, remote sensing observations from the orbiter with the Solid State Imaging (SSI) camera and the Near Infrared Mapping Spectrometer (NIMS) give 
access to the study of individual features in the Jovian atmosphere, in particular the $5 \mu \mathrm{m}$ hot spots (RoosSerote et al., 1998). ISO-SWS observations of Jupiter are complementary to those of Galileo, giving access to a large spectral range on a global scale at high spectral resolution, while the Galileo-NIMS observations are done with a high spatial but a relatively low spectral resolution. Some examples of this complementarity will be given in the following.

In this paper, we present a review of the ISO spectra of Jupiter and Saturn over the 2.3-45 $\mu \mathrm{m}$ spectral range, including both the reflected sunlight component below about $4 \mu \mathrm{m}$ and the thermal emission at longer wavelengths. The results are then discussed in the light of previous studies, in particular those derived from the Voyager Infra Red Interferometric Spectrometer (IRIS) data and the recent Galileo results on Jupiter. The discussion is extended to the four giant planets in a few relevant cases $(\mathrm{D} / \mathrm{H}$ determination, detection of an external oxygen source).

\section{The ISO spectra}

The ISO satellite (Kessler et al., 1996) consisted of a $60 \mathrm{~cm}$ helium-cooled telescope equipped with four focal plane instruments, a camera (Cesarsky et al., 1996), a photometer (Lemke et al., 1996), a shortwavelength spectrometer SWS (de Graauw et al., 1996), and a long-wavelength spectrometer LWS (Clegg et al., 1996). Data on Jupiter and Saturn were obtained with the camera and the two spectrometers. The instrumental characteristics of the two ISO spectrometers are summarized in Table 1 . They cover the ranges $2.3-45 \mu \mathrm{m}$ and $45-180 \mu \mathrm{m}$, respectively; their grating mode has a mean resolving power of about 1500 (SWS) and 200 (LWS). They are also equipped with a Fabry-Pérot mode which covers the range 11.5-44.5 $\mu \mathrm{m}$ for SWS, and the whole LWS range, with a resolving power of about $20,000-35,000$ and $8000-10,000$ respectively. The SWS grating spectra were recorded with an aperture of $14^{\prime \prime} \times 20^{\prime \prime}$ below $12 \mu \mathrm{m}$ and $14^{\prime \prime} \times 27^{\prime \prime}$ above.

Jupiter and Saturn spectra were recorded both in the grating and Fabry-Pérot mode of SWS and LWS through the Core Programme and the Open Time Proposals. In the case of Jupiter, SWS data were recorded with the aperture (aligned along the $\mathrm{N}-\mathrm{S}$ axis) centered at the center and at the poles of the planet. Because of the strong Jupiter thermal flux, the disk-centered spectra were not usuable beyond about $20 \mu \mathrm{m}$ due to saturation effects. In the case of Saturn, nearly the whole disk entered the SWS aperture. In the case of the LWS data, both planets were smaller than the field of view (1.65').

The first results concerning Jupiter and Saturn
Table 1

Instrumental characteristics of the ISO spectra

\begin{tabular}{lrrr}
\hline Instrument & $\begin{array}{l}\text { Aperture } \\
\left(' x^{\prime}\right)\end{array}$ & $\begin{array}{l}\text { Wavelength } \\
(\mu \mathrm{m})\end{array}$ & $\begin{array}{l}\text { Resolution } \\
(R=\lambda / \Delta \lambda)\end{array}$ \\
\hline SWS Grating & $14-20$ & $2.38-2.60$ & $1870-2110$ \\
& $14-20$ & $2.60-3.02$ & $1470-1750$ \\
& $14-20$ & $3.02-3.52$ & $1750-2150$ \\
& $14-20$ & $3.52-4.05$ & $1290-1540$ \\
& $14-20$ & $4.05-5.30$ & $1540-2130$ \\
SWS Grating & $14-20$ & $5.30-7.00$ & $930-1250$ \\
& $14-20$ & $7.00-12.0$ & $1240-2450$ \\
& $14-27$ & $12.0-16.0$ & $1250-1760$ \\
& $14-27$ & $16.0-19.5$ & $1760-2380$ \\
SWS FP & $14-27$ & $19.5-27.5$ & $980-1270$ \\
& $20-27$ & $27.5-29.5$ & 1300 \\
& $20-33$ & $29.5-45.2$ & $1020-1630$ \\
& $10-39$ & $11.4-12.2$ & $20,600-24,000$ \\
& $10-39$ & $12.2-16.0$ & $24,000-32,000$ \\
LWS Grating & $10-39$ & $16.0-19.0$ & $32,000-34,500$ \\
& $10-39$ & $19.0-26.0$ & $34,500-35,500$ \\
LWS FP & $17-40$ & $26.0-44.5$ & $29,000-31,000$ \\
& $99-99$ & $45-90$ & $155-310(\Delta \lambda=0.29 \mu \mathrm{m})$ \\
& (circular) & $90-190$ & $150-317(\Delta \lambda=0.60 \mu \mathrm{m})$ \\
& & $45-90$ & $8000-10,000$ \\
& & $90-190$ & $9000-10,000$ \\
\hline \multirow{5}{*}{ “ } & & &
\end{tabular}

obtained from the ISO spectra are reported in Encrenaz et al. (1996a, 1997), de Graauw et al. (1997), Feuchtgruber et al. (1997) Bézard (1998) and Bézard et al. (1998).

Fig. 1 shows the SWS spectrum of Jupiter, Saturn and Neptune between 2.3 and $16 \mu \mathrm{m}$. Fig. 1 illustrates the very large dynamical range of the spectra (over $10^{4}$ for Jupiter) and the high sensitivity of the data, the 3 $\sigma$ noise being lower than $1 \mathrm{Jy}$. In the case of Jupiter, however, instrumental fringing problems (Schaeidt et al., 1996) significantly reduce the signal to noise between 12 and $16 \mu \mathrm{m}$; their correction, which requires the development of a specific software, is in progress.

\section{The $2.7 \mu \mathrm{m}$ window: evidence for $\mathrm{NH}_{3}$-ice signature on Jupiter}

The spectrum of Jupiter and Saturn between 2.3 and $4 \mu \mathrm{m}$ is dominated by solar radiation, reflected or scattered and partly absorbed by the atmosphere. The main absorbers are $\mathrm{CH}_{4}$ and $\mathrm{H}_{2}$ for both planets. In addition, $\mathrm{NH}_{3}$ and $\mathrm{PH}_{3}$ gaseous absorptions contribute significantly to the spectra.

Fig. 2 shows the Jupiter and Saturn ISO grating spectra between 2.55 and $3.25 \mu \mathrm{m}$. The $2.7 \mu \mathrm{m}$ window is bracketed by the strong $v_{3}$ band of $\mathrm{CH}_{4}$ centered at $3.3 \mu \mathrm{m}$ on the red side, and by $\mathrm{CH}_{4}$ combination bands on the blue side. The Jupiter and Saturn spectra in this window are remarkably different, with the Saturn spectrum being even brighter than Jupiter's at $3 \mu \mathrm{m}$ contrary to expectations since, for similar prop- 


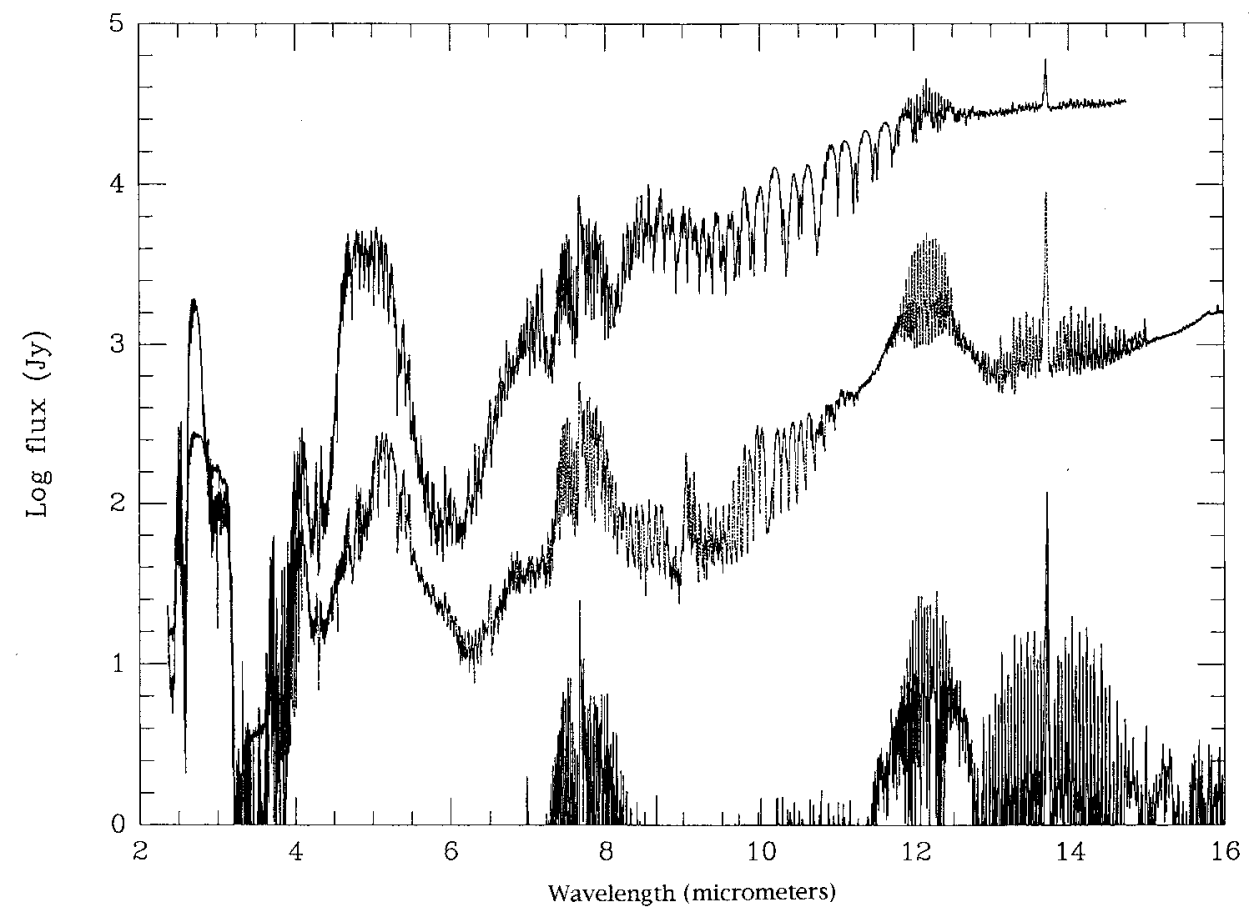

Fig. 1. The SWS grating spectrum of Jupiter between 2 and $16 \mu \mathrm{m}$. The resolving power is about 1500 . The Uranus spectrum only shows the $\mathrm{C}_{2} \mathrm{H}_{2}$ band at $13.7 \mu \mathrm{m}$, about 3 times weaker than on the Neptune spectrum. Uranus and Neptune are not detected below $7 \mu \mathrm{m}$ with SWS.

erties of their atmospheres, it would be expected to be more than 4 times weaker. The Jupiter spectrum shows for the first time the $v_{1}$ band of gaseous $\mathrm{NH}_{3}$, centered at $3.0 \mu \mathrm{m}$. However, this absorption alone cannot explain the shape of the spectrum, which suggests the presence of a broad signature of ice, likely to be associated with the $\mathrm{NH}_{3}$ cloud (Encrenaz et al., 1996a). Brooke et al. (1998) have modeled this part of the Jupiter spectrum including multiple scattering by spherical cloud particles, and have obtained a good fit of the data with a two-cloud model including $\mathrm{NH}_{3}$ ice particles of about $10 \mu \mathrm{m}$ size in the upper cloud near 0.55 bar.

These results agree reasonably well with previous work by Marten et al. (1981), Orton et al. (1982), West et al. (1986) and Gierasch et al. (1986); they differ, in contrast with the conclusions derived from Carlson et al. (1993, 1994) and from Irwin et al. (1998). Carlson et al. (1993, 1994) favored a bimodal $(3 \mu \mathrm{m}, 100 \mu \mathrm{m})$ distribution of particles based on the absence of $\mathrm{NH}_{3}$ ice resonant absorption features in Voyager IRIS spectra $(5-50 \mu \mathrm{m})$ and the comparison of 5 and $50 \mu \mathrm{m}$ radiances. Irwin et al. (1998) suggest, from NIMS-Galileo spectra in the $1-5 \mu \mathrm{m}$ range, a two-layer model with a combination of small and large $(50 \mu \mathrm{m}) \mathrm{NH}_{4} \mathrm{SH}$ particles in the lower cloud and very small particles $(0.75 \mu \mathrm{m})$ in the $\mathrm{NH}_{3}$ cloud. The composition of the upper cloud, which is near the level where ammonia condenses, appears to be more complex than simple crystals of condensed $\mathrm{NH}_{3}$ (Irwin et al., 1998). The $v_{1}$ band of gaseous $\mathrm{NH}_{3}$, centered at $3 \mu \mathrm{m}$, superimposed over the solid absorption, is well fitted with a saturated $\mathrm{NH}_{3}$ distribution above the $\mathrm{NH}_{3}$ cloud base, with a constant $\mathrm{NH}_{3} / \mathrm{H}_{2}$ ratio of $2.2 \times 10^{-4}$ (corresponding to the solar $\mathrm{N} / \mathrm{H}$ value) below the $\mathrm{NH}_{3}$ cloud level (Brooke et al., 1998).

The SWS grating spectrum of Saturn, in contrast with Jupiter, shows no evidence for a signature of solid $\mathrm{NH}_{3}$ around $3 \mu \mathrm{m}$. On Saturn, the $\mathrm{NH}_{3}$ condensation takes place at deeper levels than on Jupiter, because of the lower temperature in the troposphere. The lack of any observable spectral feature could be due to different sizes of the particles, or to a possible combination with other solid compounds. The spectrum of Saturn in this region is characterized by an absorption due to phosphine, as previously observed in airborne spectra (Larson et al., 1980; Kerola et al., 1997). A line by line calculation of the synthetic spectrum of Saturn is not presently feasible, because of the lack of available spectroscopic data with regard to the $\mathrm{PH}_{3}$ bands around $3 \mu \mathrm{m}$.

\section{The $\mathrm{CH}_{4}$ emission at $3.3 \mu \mathrm{m}$}

A major result of ISO has been the first detection of the emission from the $v_{3} \mathrm{CH}_{4}$ band at $3.3 \mu \mathrm{m}$, both on Jupiter and Saturn (Fig. 3). Synthetic calculations were first made under the assumption that most of the flux originates from thermal emission; it would thus have 

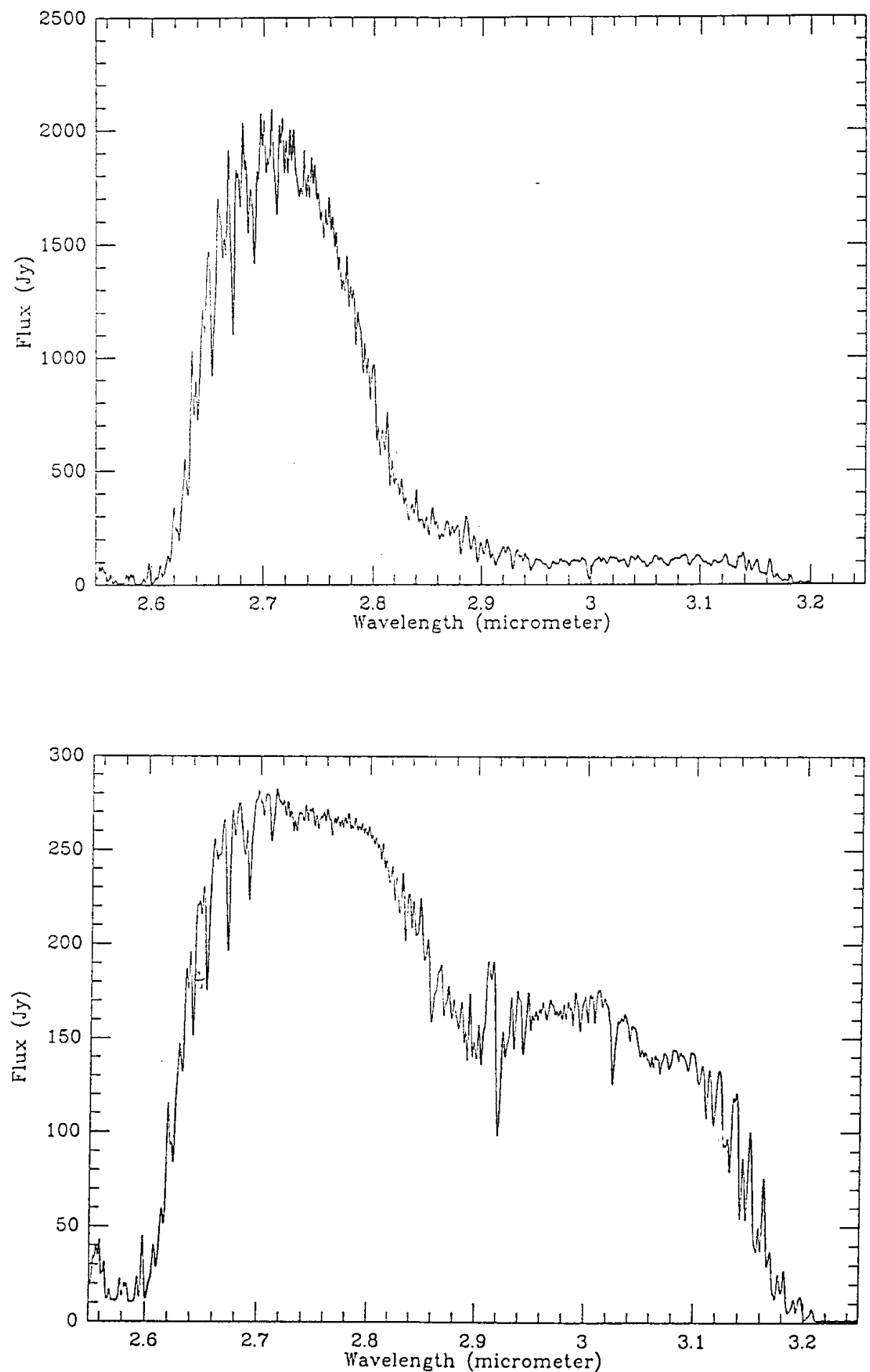

Fig. 2. The ISO SWS grating spectra of Jupiter and Saturn between 2.55 and $3.25 \mu \mathrm{m}$ from Encrenaz et al. (1997).

been an indicator of the temperature of the upper stratosphere. Preliminary calculations indicated a temperature of about $800 \mathrm{~K}$ at $0.16 \mu$ bar in the case of Jupiter (Encrenaz et al., 1996a). However, a more refined analysis has demonstrated that fluorescence involving higher transition levels is required to obtain a good fit of both the $Q$-branch and the $P$ - and $R$-multiplets
(Drossart et al., 1998, 1999; Fouchet et al., 1999). The reanalysis of the $3.3 \mu \mathrm{m}$ emission in the $\mathrm{CH}_{4}$ bands of Jupiter and Saturn (Drossart et al., 1998) has shown that a very good fit of the SWS spectrum is obtained with a model of fluorescence emission in the $v_{3}$ band of $\mathrm{CH}_{4}$ and its overtones at 2.3 and $1.7 \mu \mathrm{m}$. The fluorescence is dependent of the column density of $\mathrm{CH}_{4}$ in 

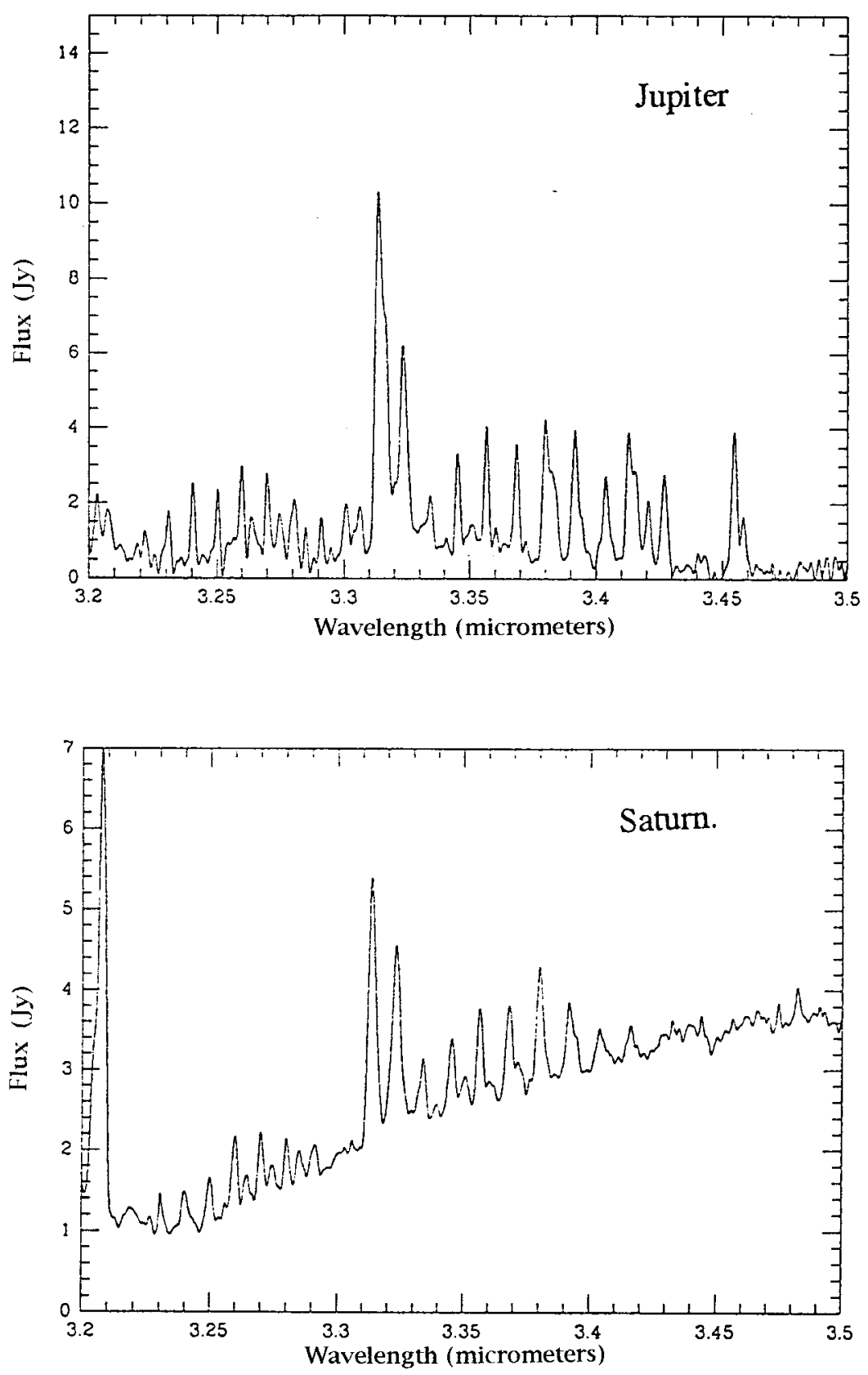

Fig. 3. The $v_{3} \mathrm{CH}_{4}$ band on Jupiter and Saturn observed with the ISO SWS grating, from Encrenaz et al. (1997).

the non-LTE part of the atmosphere, which itself depends upon the eddy diffusion coefficient. It is therefore possible to constrain the Jupiter and Saturn eddy diffusion coefficients from these measurements. Preliminary estimates indicate values at the homopause of $6 \times 10^{6} \mathrm{~cm}^{2} \mathrm{~s}^{-1}$ for Jupiter and $4 \times 10^{7} \mathrm{~cm}^{2} \mathrm{~s}^{-1}$ for Saturn (Drossart et al., 1999).

The $\nu_{4} \mathrm{CH}_{4}$ band at $7.7 \mu \mathrm{m}$ and the $\mathrm{H}_{2}$ quadrupole lines at 17 and $28 \mu \mathrm{m}$ allow us to probe the thermal profile in the lower stratospheres of Jupiter and Saturn. Recent observations have raised an important question about the upper stratospheric thermal profile.
The Galileo Probe accelerometer has measured high thermospheric temperatures in Jupiter $(T>800 \mathrm{~K}$ at the $0.01-\mu$ bar level), which implies an integrated column heating rate of $0.4 \mathrm{erg} \mathrm{cm}{ }^{-2} \mathrm{~s}^{-1}$ (Young et al., 1997). Two interpretations of this heating rate have been provided, one by gravity wave breaking (Young et al., 1997), the second by the precipitation of energetic particles, also responsible for the $\mathrm{X}$-ray emissions observed by the ROSAT satellite in the equatorial regions (Waite et al., 1997). According to a recent reanalysis by Matcheva and Strobel (1998), the interpretation by gravity wave heating only seems to be 
inconsistent with the amplitude of the wave structure in Galileo's thermal profile, and several heating sources may be needed, as was previously discussed by Atreya et al. (1979) following the Voyager measurements of the upper atmospheric temperature. The ISO observations provide another piece of information concerning this problem (Fouchet et al., 1999). A synthetic calculation using the Galileo thermal profile and Gladstone et al.'s (1996) $\mathrm{CH}_{4}$ vertical distribution provide too high a methane emission at $7.7 \mu \mathrm{m}$.

The $3.3 \mu \mathrm{m}$ spectrum of Jupiter shows interesting differences between the center and the poles. Indeed, $\mathrm{H}_{3}^{+}$lines dominate the polar spectra, while they are
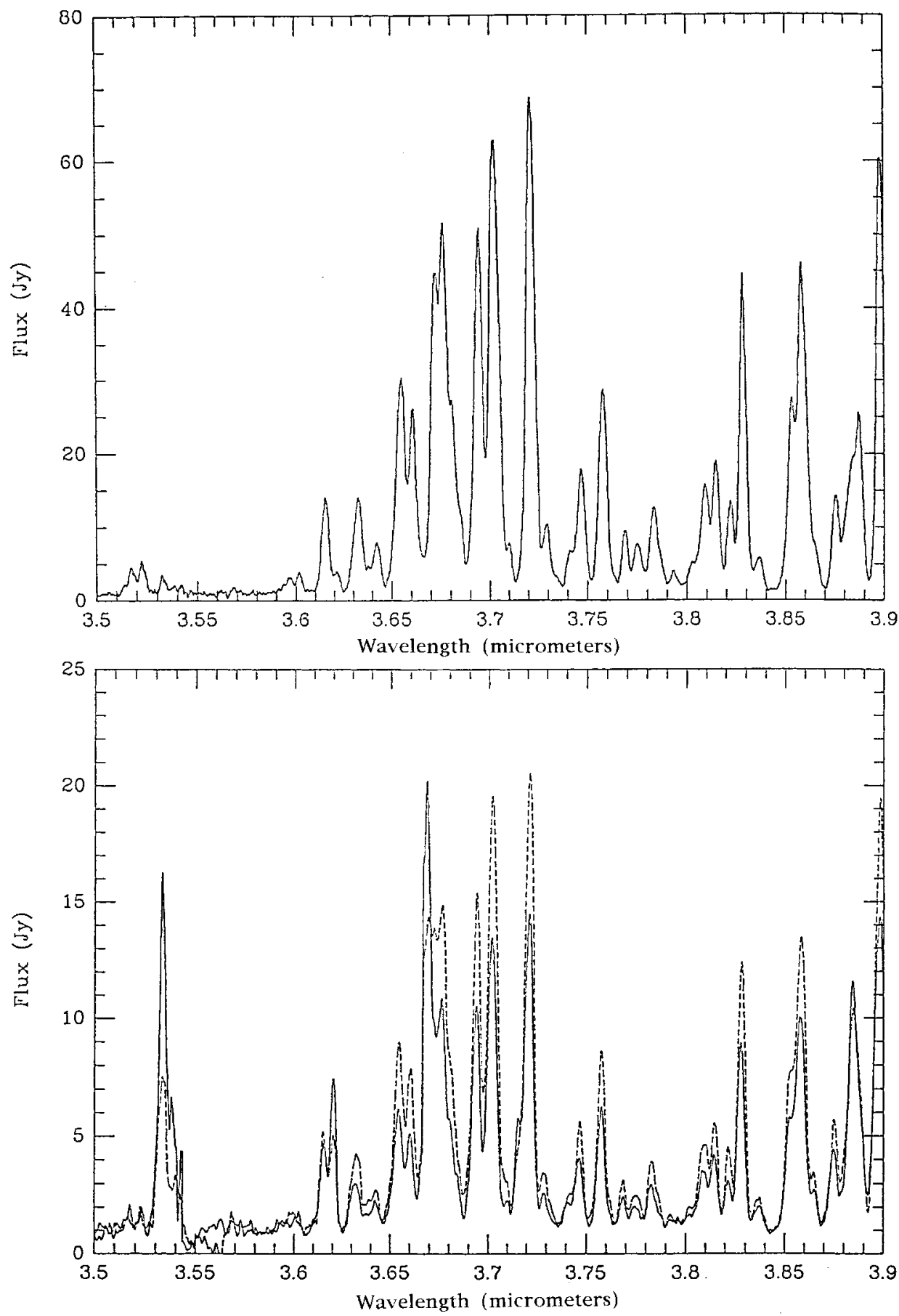

Fig. 4. $\mathrm{H}_{3}^{+}$emissions on Jupiter observed with the ISO-SWS grating between 3.5 and $3.9 \mu \mathrm{m}$. Top: disk center; bottom: north pole (dashed line) and south pole (solid line). 

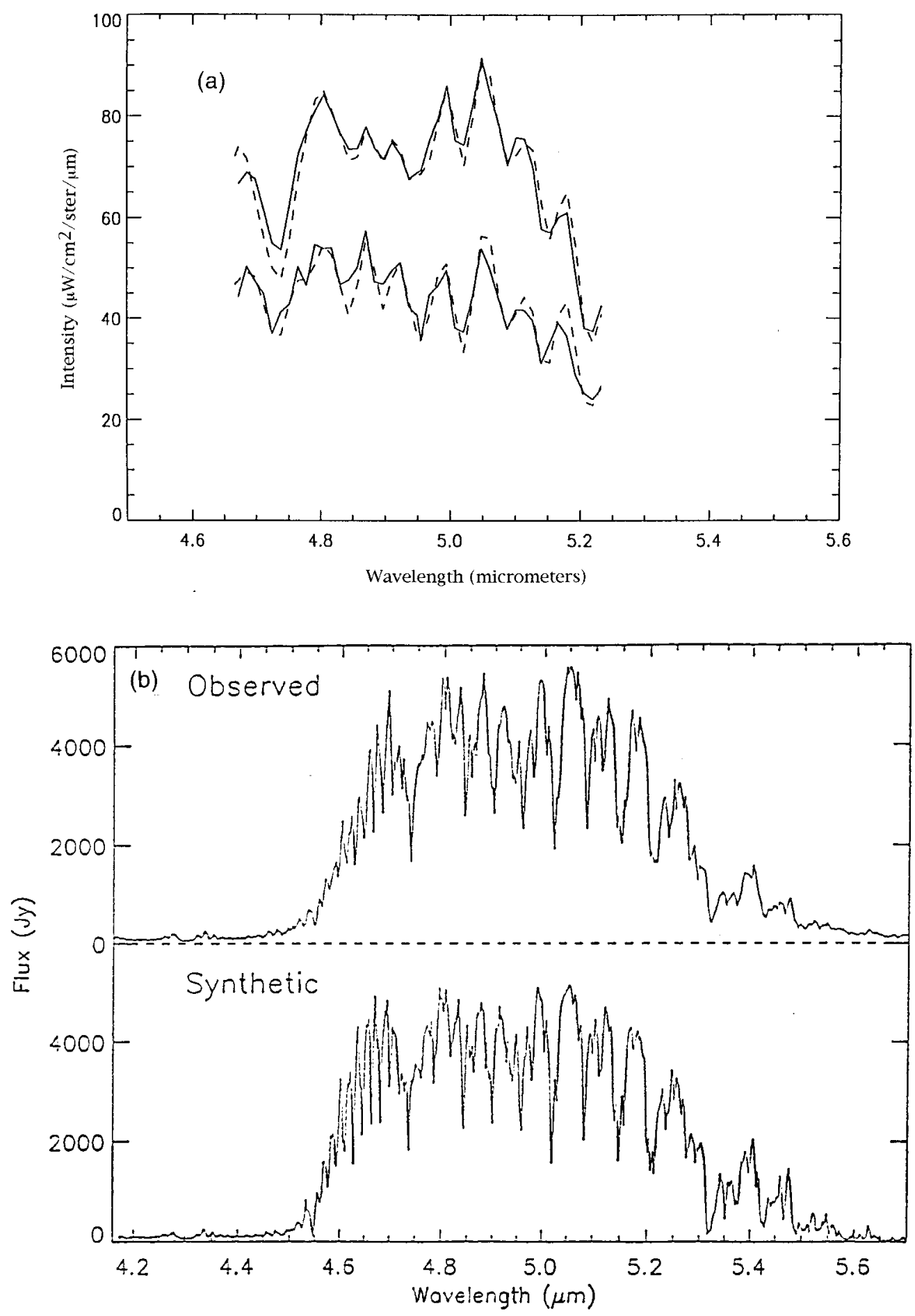

Fig. 5. The 5- $\mu \mathrm{m}$ window on Jupiter. Top: NIMS spectra at the center and at the edge of a hot spot (Roos-Serote, 1997). The fits correspond to $1 \%$ saturation water profile (upper curve, spot center) and $6 \%$ saturation (spot edge, lower curve). Bottom: disk-centered ISO-SWS grating spectrum, compared to a synthetic model, including a $1 \%$ saturation profile of $\mathrm{H}_{2} \mathrm{O}$ (Encrenaz et al., 1996a).

not detectable at the center (Fig. 4). These data will be used to constrain the $\mathrm{H}_{3}^{+}$abundance and temperature profile in the very high stratosphere at the poles of Jupiter, as has been studied from ground-based spectroscopy (Lam et al., 1997).

\section{The $5 \mu \mathrm{m}$ window: detection of Saturn's tropospheric water}

The 5- $\mu \mathrm{m}$ spectra of Jupiter and Saturn probe deep tropospheric levels (4-8 bars in the case of Jupiter, 2-5 


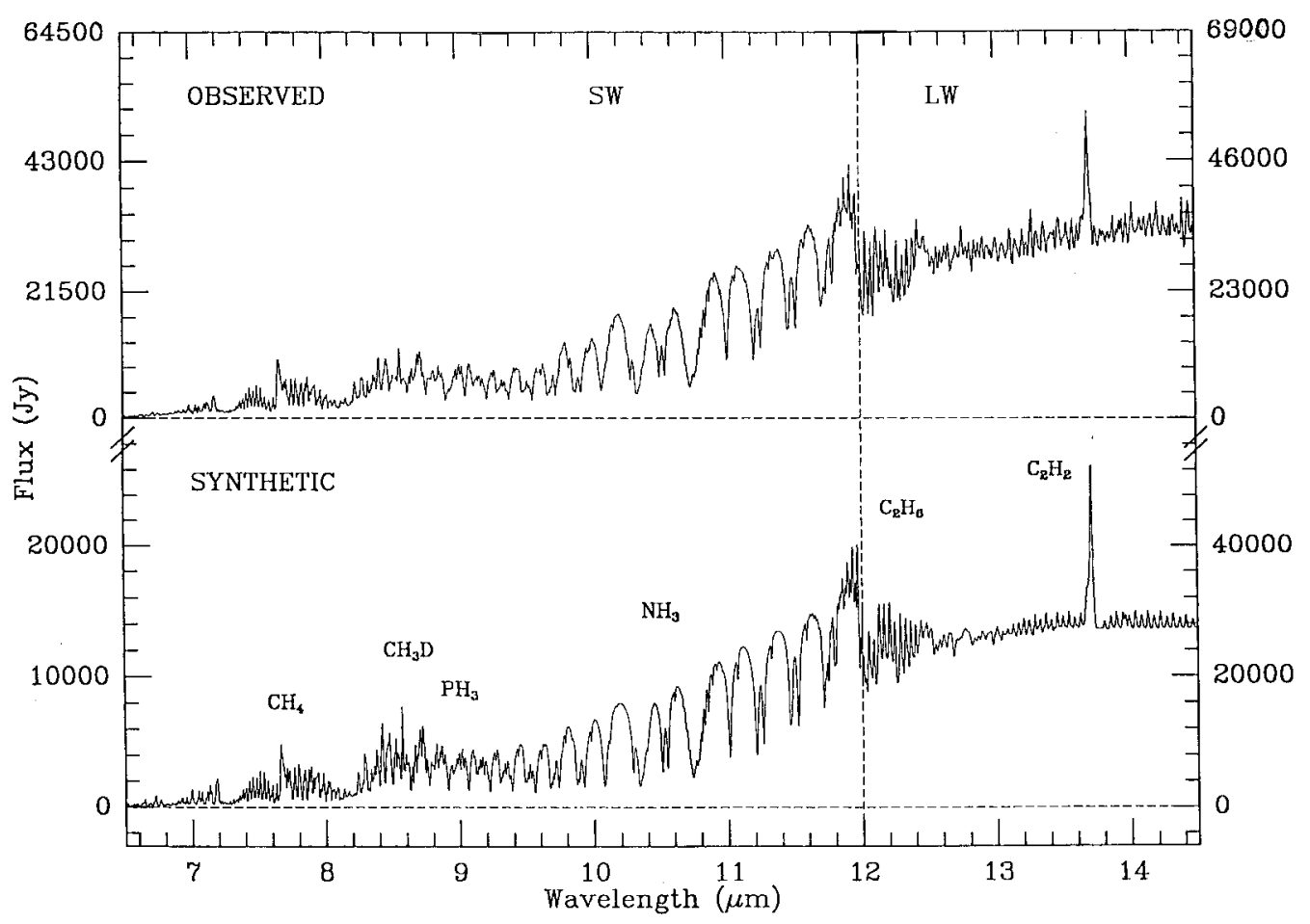

Fig. 6. The 6-14 $\mu \mathrm{m}$ spectrum of Jupiter. Top: ISO-SWS grating; bottom: synthetic spectrum. The figure is taken from Encrenaz et al. (1996a).

bars in the case of Saturn). The ISO SWS grating spectra of Jupiter provide an interesting complement to the spectra obtained by the NIMS (Near Infrared Mapping Spectrometer) instrument aboard the Galileo orbiter with a lower spectral resolution $(R=270)$, but a much higher spatial resolution $(300-800 \mathrm{~km})$. In particular, NIMS data show that the water abundance is often minimum at the center of the hot spots, where the thermal emission, coming from deeper levels, is maximum (Fig. 5a). The analysis of the ISO spectrum (Encrenaz et al., 1996a) confirmed the depletion of water in the hot spots, which provide the strongest contribution to the $5 \mu \mathrm{m}$ flux in the ISO spectra (Fig. $5 b)$. This result is in agreement with the probe results (Niemann et al., 1996, 1998) and with the interpretation of the NIMS spectra at $5 \mu \mathrm{m}$ (Carlson et al., 1996; Roos-Serote et al., 1998; Irwin et al., 1998). It is consistent with the scenario according to which the hot spots are dry and are regions of subsidence; if this model is correct, no information about the $\mathrm{O} / \mathrm{H}$ ratio in the deep troposphere can be retrieved from the observations of the hot spots alone, unless a probe descended to pressures far in excess of the 20-bar level reached by the Galileo probe. Apart from $\mathrm{H}_{2} \mathrm{O}$, the $5 \mu \mathrm{m}$ ISO spectrum of Jupiter provides new information on the tropospheric vertical distributions of $\mathrm{NH}_{3}$ and $\mathrm{PH}_{3}$, mainly due to the high sensitivity of the data. In particular, the retrieved $\mathrm{NH}_{3}$ vertical distribution is found similar to the Galileo Probe measurements (Folkner et al., 1998) at least down to the 4-bar pressure level where it reaches a mixing ratio of $3.5 \times 10^{-4}$, i.e. 1.6 times the solar value (Fouchet et al., 1999). No information is retrieved at deeper levels. The ISO result is thus consistent with the results of the Galileo probe (Folkner et al., 1998); it is slightly higher than, but still marginally compatible with the value of de Pater and Massie (1985) who conclude to a $\mathrm{N} / \mathrm{H}$ ratio of $1.0-1.3$ times the solar value from globally averaged VLA data of Jupiter.

In the case of Saturn, the ISO spectrum has provided the first detection of water in the deep troposphere (de Graauw et al., 1997; Drossart, 1998). As in the case of Jupiter, the derived $\mathrm{H}_{2} \mathrm{O}$ mixing ratio $\left(2 \times 10^{-7}\right.$ below the 3 bar level) corresponds to a strongly undersaturated profile. It is tempting to invoke the same mechanism as on Jupiter, with hot spots being dry regions of subsidence. Unlike Jupiter, however, the disk of Saturn does not show a few welllocalized hot spots, mostly associated with belts, but only large areas with higher brightness temperatures which have a much lower contrast than on Jupiter. More high-resolution imaging will be needed to study the circulation mechanism on Saturn and to explain the low abundance of water.

\section{The 6-14 $\mu \mathrm{m}$ region: probing the tropopause region}

On both Jupiter and Saturn, the 6-14 $\mu \mathrm{m}$ continuum radiation, constrained by the hydrogen and 


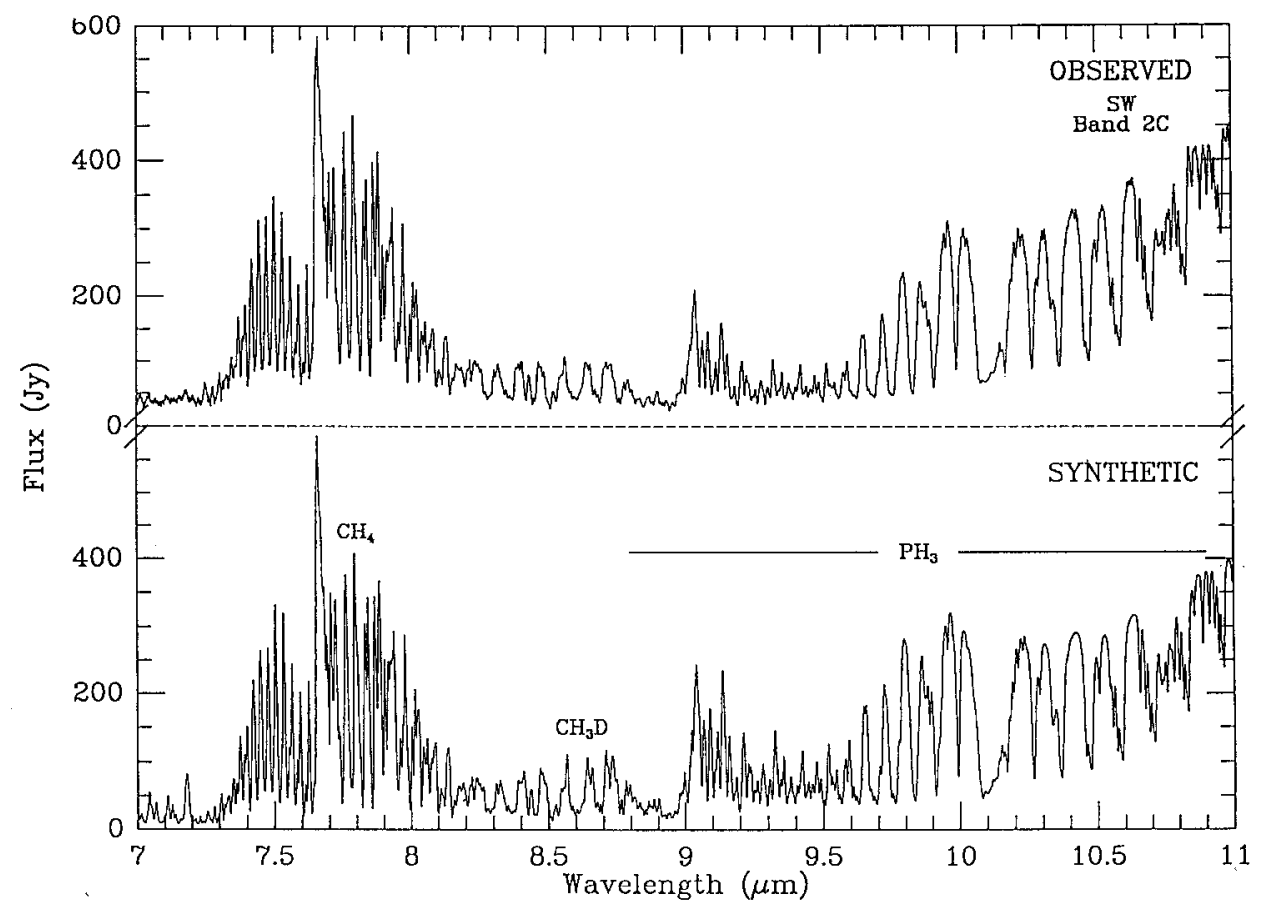

Fig. 7. The 7-11 $\mu \mathrm{m}$ spectrum of Saturn. Top: ISO-SWS grating; bottom: synthetic spectrum. The figure is taken from de Graauw et al. (1997).

helium pressure-induced spectrum (and, in the case of Jupiter, by the $\mathrm{NH}_{3}$ cloud), comes from a region just below and above the tropopause, so that the spectrum exhibits both emission lines $\left(\mathrm{CH}_{4}\right.$ at $7.7 \mu \mathrm{m}, \mathrm{C}_{2} \mathrm{H}_{6}$ at $12.5 \mu \mathrm{m}, \mathrm{C}_{2} \mathrm{H}_{2}$ at $\left.13.7 \mu \mathrm{m}\right)$ and absorption features $\left(\mathrm{CH}_{3} \mathrm{D}\right.$ and $\mathrm{NH}_{3}$ on Jupiter, $\mathrm{CH}_{3} \mathrm{D}$ and $\mathrm{PH}_{3}$ in Saturn; Figs. 6 and 7).

In the case of Jupiter, a complete analysis of the spectrum has been achieved by Fouchet et al. (1998) who also derive a ${ }^{15} \mathrm{NH}_{3} /{ }^{14} \mathrm{NH}_{3}$ significantly smaller than the solar value (the best fit corresponds to a ${ }^{14} \mathrm{~N} /{ }^{15} \mathrm{~N}$ ratio between 500 and 900 , whereas the solar value is 270 ).

In the case of Saturn (Fig. 7), a preliminary analysis from the inversion of the $\mathrm{CH}_{4} v_{4}$ band indicates a thermal profile colder than the Voyager profile in the stratosphere, by $7 \mathrm{~K}$ at $0.5 \mathrm{mbar}$, and warmer in the troposphere, by about $3 \mathrm{~K}$ at $150 \mathrm{mb}$ (de Grauuw et al., 1997; Fig. 7). In this inversion, following Courtin et al. (1984), the Voyager-IRIS value of $4.4 \times 10^{-4}$ was assumed for the $\mathrm{CH}_{4} / \mathrm{H}_{2}$ ratio The following results are also inferred by de Graauw et al. (1997); the $\mathrm{PH}_{3}$ vertical distribution has a mixing ratio of $4.5 \times 10^{-6}$ below $600 \mathrm{mbar}$ and decreases to $2.5 \times 10^{-6}$ at 300 mbar with a sharp cut-off above this level, in contrast with the Voyager results (Courtin et al., 1984) but in agreement with the $\mathrm{PH}_{3}$ distribution retrieved from far-IR ISO data using the LWS grating (Davis et al., 1996). The $\mathrm{C}_{2} \mathrm{H}_{6}$ emission is well fitted with a constant mixing ratio of $4 \times 10^{-6}$ above the 10 mbar level, in agreement with the Voyager results
(Courtin et al., 1984), while the $\mathrm{C}_{2} \mathrm{H}_{2}$ best fit corresponds to a mixing ratio of $3.5 \times 10^{-6}$ at $0.1 \mathrm{mbar}$ decreasing to $2.5 \times 10^{-7}$ at $1 \mathrm{mbar}$, i.e. slightly higher than the Voyager results (Courtin et al., 1984).

\section{The 14-17 $\mu \mathrm{m}$ range: detection of $\mathrm{CO}_{2}$ and new hydrocarbons}

Several new species have been detected in this range. First, the $Q$-branch of the $\mathrm{CO}_{2} v_{2}$ band has been detected on both Saturn (de Graauw et al., 1997; Feuchtgruber et al, 1997) and Jupiter (Lellouch et al., 1998). The Saturn abundance corresponds to $3 \times 10^{-10}$ above the 10-mbar pressure level; the analysis of the $\mathrm{CO}_{2}$ emission on Jupiter, at the disk center and at the poles, is presently underway. It can be noted that $\mathrm{CO}_{2}$ was also detected in the upper stratosphere of Neptune; the implications of this result are discussed in Section 8.

New hydrocarbons have been detected, especially on Saturn; $\mathrm{CH}_{3} \mathrm{C}_{2} \mathrm{H}$ (propyne, or methylacetylene) and $\mathrm{C}_{4} \mathrm{H}_{2}$ (diacetylene) are observed in the Saturn spectrum at 15.80 and $15.92 \mu \mathrm{m}$ respectively, with respective mixing ratios of $6 \times 10^{-10}$ and $9 \times 10^{-11}$ above the 10 mbar level (de Graauw et al., 1997; Fig. 8); $\mathrm{C}_{6} \mathrm{H}_{6}$ is detected in the wing of a $\mathrm{C}_{2} \mathrm{H}_{2}$ multiplet, at $14.84 \mu \mathrm{m}$ (Bézard, 1998). $\mathrm{CH}_{3}$ is detected at $16.5 \mu \mathrm{m}$, with a mixing ratio peaking at $2.5 \times 10^{-7}$ at about $0.1 \mu$ bar (Bézard et al., 1998). As discussed by Bézard et al. (1998), the synthetic spectrum of $\mathrm{CH}_{3}$, calculated from 


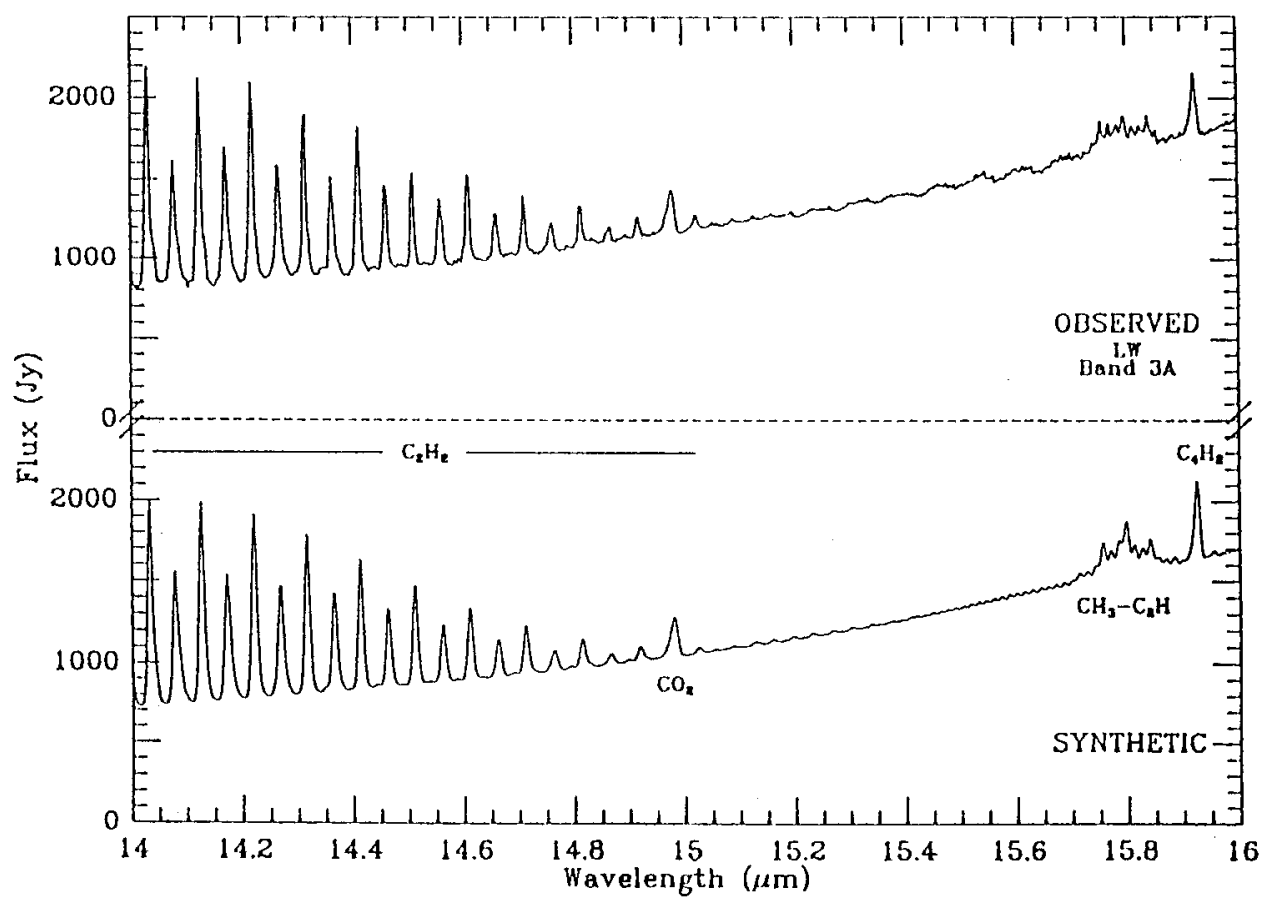

Fig. 8. The 14-16 $\mu \mathrm{m}$ spectrum of Saturn. Top: ISO-SWS grating spectrum; bottom: synthetic spectrum. $\mathrm{The}^{\mathrm{emissions}}$ of $\mathrm{CO}_{2}, \mathrm{CH}_{3} \mathrm{C}_{2} \mathrm{H}$ and $\mathrm{C}_{4} \mathrm{H}_{2}$ are detected (de Graauw et al., 1997; Encrenaz et al., 1997).

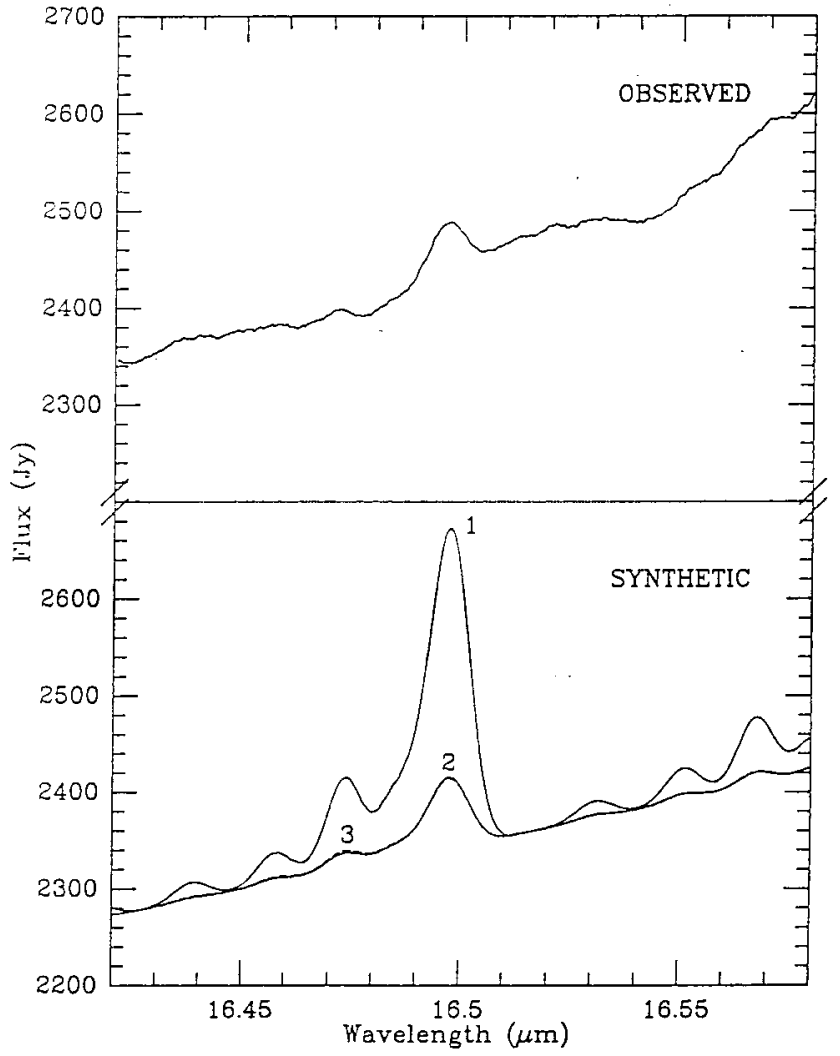

Fig. 9. First detection of $\mathrm{CH}_{3}$ on Saturn. Top: ISO SWS grating spectrum. Bottom: synthetic spectra: (1) nominal; (2) reduced value of the eddy diffusion coefficient; (3) enhanced value of the $\mathrm{CH}_{3}$ recombination rate. The figure is taken from Bézard et al. (1998). current photochemical models yields a $\mathrm{CH}_{3}$ emission which is about 5 times stronger than the observed flux (Fig. 9); other models yield a $\mathrm{CH}_{3}$ column abundance at least 10 times greater than observed (Ollivier et al., 1998; Atreya et al., 1999). A possible way of reconciling the model and the data would be to use a value of the eddy diffusion coefficient which would be about a factor 100 lower than the previous Voyager results; another possibility could be that the recombination rate of $\mathrm{CH}_{3}\left(2 \mathrm{CH}_{3} \rightarrow \mathrm{C}_{2} \mathrm{H}_{6}\right)$, presently unknown at low temperature, has been underestimated. Low temperature laboratory data of this coefficient would be needed to resolve this issue (Atreya et al., 1999). Table 2 summarizes the abundances derived from ISO and previous observations for the hydrocarbon stratospheric species of the giant planets.

\section{Detection of water in the upper stratosphere $(\lambda=28$ $45 \mu \mathrm{m})$}

A major result of the ISO observations is the unexpected detection of water in the upper stratospheres of the four giant planets (Feuchtgruber et al., 1997; Lellouch et al., 1997a,b; Fig. 10) and of Titan (Coustenis et al., 1998). Water was searched for in Titan's stratosphere, because of the earlier detection of $\mathrm{CO}$ (Lutz et al., 1983) and $\mathrm{CO}_{2}$ (Samuelson et al., 1983), and was also searched for on Saturn because of 
Table 2

ISO measurements of hydrocarbons in the stratospheres of the giant planets

\begin{tabular}{|c|c|c|c|c|}
\hline Species & Jupiter & Saturn & Uranus & Neptune \\
\hline $\begin{array}{l}\mathrm{CH}_{4} \\
\mathrm{CH}_{3} \mathrm{D} \\
\mathrm{C}_{2} \mathrm{H}_{2}\end{array}$ & $\begin{array}{l}2.1 \times 10^{-3 \mathrm{a}, \mathrm{c}} \\
2.5 \times 10^{-7 \mathrm{c}}\end{array}$ & $\begin{array}{l}4.4 \times 10^{-3 \mathrm{a}, \mathrm{d}} \\
3.2 \times 10^{-7 \mathrm{a}, \mathrm{d}} \\
3.5 \times 10^{-6}(0.1 \mathrm{mb}) \\
2.5 \times 10^{-7}(1 \mathrm{mb}) \\
\text { - } \mathrm{a}, \mathrm{d}^{-6}\end{array}$ & $\begin{array}{l}3 \times 10^{-5}-10^{-4 a, f} \\
2-4 \times 10^{-7 f} \\
(0.1-0.3 \mathrm{mb})\end{array}$ & $\begin{array}{l}7 \times 10^{-4 \mathrm{~g}}(0.05-1 \mathrm{mb}) \\
2.2 \times 10^{-7 \mathrm{~g}} \\
1.1 \times 10^{-7 \mathrm{~g}} \\
(0.1 \mathrm{mb})\end{array}$ \\
\hline $\mathrm{C}_{2} \mathrm{H}_{6}$ & $\begin{array}{l}4.0 \times 10^{-6 \mathrm{c}} \\
(0.3-50 \mathrm{mb})\end{array}$ & $\begin{array}{l}4.0 \times 10^{-6 \mathrm{~d}} \\
(<10 \mathrm{mb})\end{array}$ & & $\begin{array}{l}1.3 \times 10^{-6 \mathrm{~g}} \\
(0.03-1.5 \mathrm{mb})\end{array}$ \\
\hline $\mathrm{CH}_{3} \mathrm{C}_{2} \mathrm{H}$ & $-\mathrm{b}, \mathrm{h}$ & $\begin{array}{l}6.0 \times 10^{-10 \mathrm{~d}} \\
(<10 \mathrm{mb})\end{array}$ & & \\
\hline $\begin{array}{l}\mathrm{C}_{4} \mathrm{H}_{2} \\
\mathrm{C}_{6} \mathrm{H}_{6}\end{array}$ & $-^{\mathrm{b}, \mathrm{i}}$ & $\begin{array}{l}9.0 \times 10^{-11 \mathrm{~d}} \\
(<10 \mathrm{mb}) \\
{ }_{\mathrm{b}, \mathrm{j}}\end{array}$ & & \\
\hline $\mathrm{CH}_{3}$ & & $\begin{array}{l}0.2-1 \times 10^{-7 \mathrm{e}} \\
(0.3 \mu \mathrm{b})\end{array}$ & & $\begin{array}{l}2-9 \times 10^{-8 \mathrm{k}} \\
(0.2 \mu \mathrm{b})\end{array}$ \\
\hline
\end{tabular}

${ }^{\text {a }}$ Assumed.

${ }^{\mathrm{b}}$ Detected.

${ }^{c}$ Encrenaz et al. (1996a).

${ }^{\mathrm{d}}$ de Graauw et al. (1997).

${ }^{\text {e }}$ Bézard et al. (1998).

${ }^{\mathrm{f}}$ Encrenaz et al. (1998).

${ }^{\mathrm{g}}$ Bézard et al. (1997).

${ }^{\text {h }}$ Fouchet et al. (1998).

${ }^{\mathrm{i}}$ Drossart et al. (1998).

${ }^{\mathrm{j}}$ Bézard (1998).

${ }^{\mathrm{k}}$ Romani et al. (1998).

Table 3

Oxygen compounds in the giant planets and Titan

\begin{tabular}{|c|c|c|c|c|c|c|}
\hline Object & $\mathrm{T}_{\min }(\mathrm{K})$ & $\mathrm{CO}_{\text {trop }}$ & $\mathrm{CO}_{\text {strat }}$ & $\mathrm{CO} 2_{\text {strat }}$ & $\mathrm{H}_{2} \mathrm{O}_{\text {trop }}$ & $\mathrm{H}_{2} \mathrm{O}_{\text {strat }}$ \\
\hline Jupiter & 105 & $1.6 \times 10^{-9 c}$ & $1.5 \times 10^{-9} ?$ & $-^{\mathrm{b}}$ & $\begin{array}{l}1.4 \times 10^{-5 d} \\
(3-5 b)^{a}\end{array}$ & $\begin{array}{l}1.5 \times 10^{-9 \mathrm{e}} \\
(<10 \mathrm{mb})\end{array}$ \\
\hline Saturn & 92 & $2 \times 10^{-9 f}$ & $2 \times 10^{-9} ?$ & $\begin{array}{l}3 \times 10^{-10 \mathrm{~g}} \\
(<10 \mathrm{mb})\end{array}$ & $\begin{array}{l}2 \times 10^{-7 g} \\
(>3 \mathrm{~b})\end{array}$ & $\begin{array}{l}2-20 \times 10^{-9 \mathrm{~h}} \\
(<0.3 \mathrm{mb})\end{array}$ \\
\hline Uranus & 55 & $<5 \times 10^{-7 i}$ & $<3 \times 10^{-8 j}$ & $\begin{array}{l}<3 \times 10^{-10 \mathrm{~h}} \\
(<2 \mathrm{mb})\end{array}$ & $?$ & $\begin{array}{l}5-12 \times 10^{-9 \mathrm{~h}} \\
(<30 \mu \mathrm{b})\end{array}$ \\
\hline Neptune & 52 & $<10^{-6 \mathrm{i}}$ & $\begin{array}{l}6 \times 10^{-7 \mathrm{k}} \\
1.2 \times 10^{-6 \mathrm{j}}\end{array}$ & $\begin{array}{l}5 \times 10^{-10} \\
(<5 \mathrm{mb})\end{array}$ & $?$ & $\begin{array}{l}1.5-3.5 \times 10^{-9 \mathrm{~h}} \\
(<0.6 \mathrm{mb})\end{array}$ \\
\hline Titan & 72 & $6 \times 10-5^{1}$ & $\begin{array}{l}4 \times 10-6^{\mathrm{m}} \\
5 \times 10^{-5 \mathrm{p}}\end{array}$ & $1.4 \times 10^{-8 n}$ & & $\begin{array}{l}8 \times 10^{-90} \\
(0.01 \mathrm{mb})\end{array}$ \\
\hline
\end{tabular}

${ }^{a}$ Variable over the disk; mean value from ISO SWS spectrum (disk-centered).

${ }^{\mathrm{b}}$ Detected.

${ }^{\mathrm{c}}$ Noll et al. (1988; 1997).

${ }^{\mathrm{d}}$ Encrenaz et al. (1996a).

${ }^{\mathrm{e}}$ Lellouch et al. (1997a; 1997b).

${ }^{\mathrm{f}}$ Noll et al. (1986).

${ }^{\mathrm{g}}$ de Graauw et al. (1997).

${ }^{\text {h }}$ Feuchtgruber et al. (1997).

${ }^{\mathrm{i}}$ Encrenaz et al. (1996b).

${ }^{\mathrm{j}}$ Marten et al. (1993).

${ }^{\mathrm{k}}$ Rosenqvist et al. (1992).

${ }^{1}$ Lutz et al. (1983).

${ }^{\mathrm{m}}$ Marten et al. (1988).

${ }^{\mathrm{n}}$ Coustenis et al. (1993).

${ }^{\circ}$ Coustenis et al. (1998).

${ }^{\mathrm{p}}$ Gurwell and Muhleman (1995). 

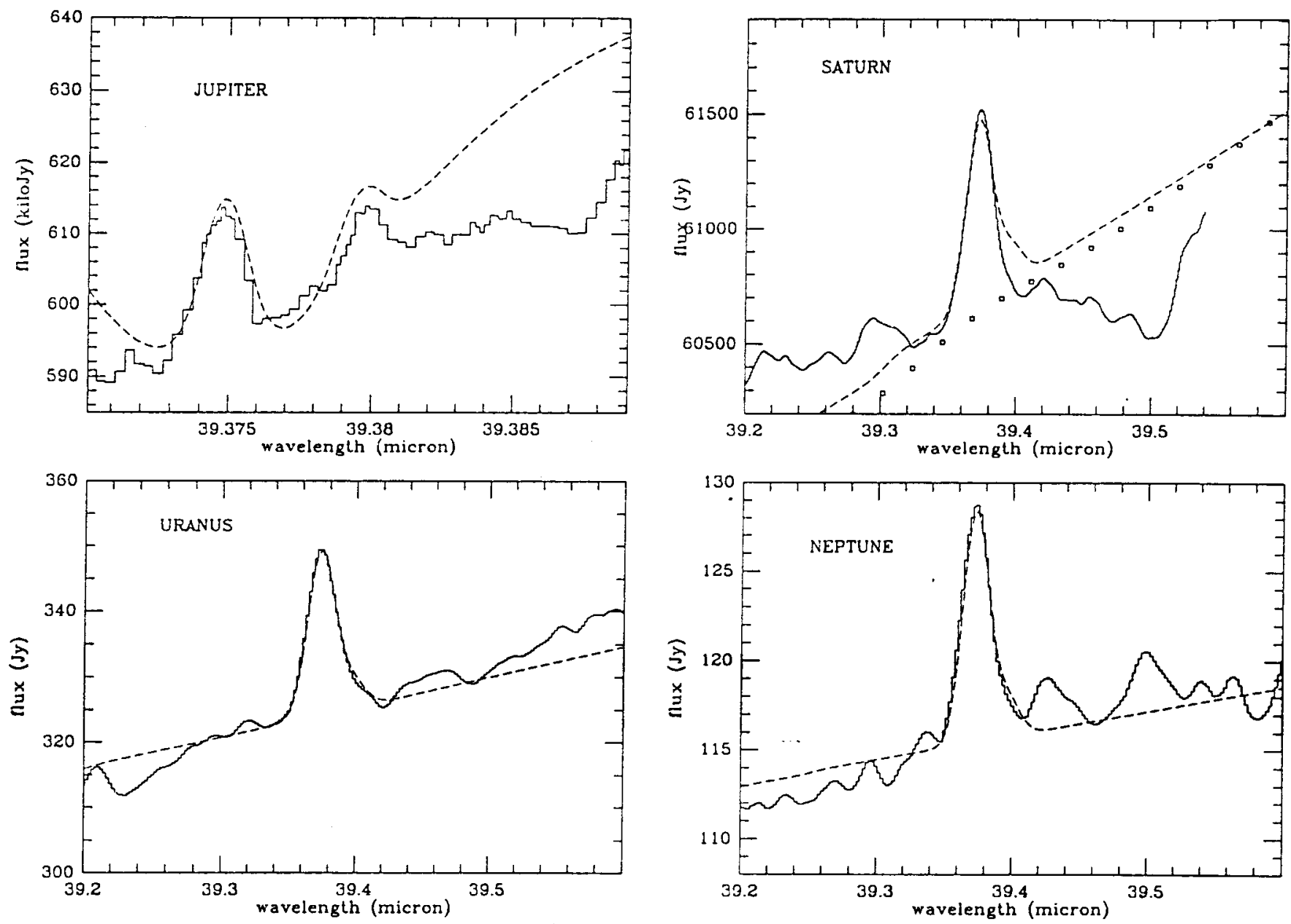

Fig. 10. Detection of stratospheric water in the giant planets. The ISO data are taken in the FP mode for Jupiter and in the grating mode for the three other planets. The figure is taken from Lellouch et al. (1997a; 1997b).

the possible sputtering of water from its ring system, but was not expected on the other giant planets.

About six emission lines of water were detected between 28 and $45 \mu \mathrm{m}$ in the SWS grating spectrum of Saturn, Uranus and Neptune (Feuchtgruber et al., 1997). In the case of Titan, two lines were detected, also in the grating mode (Coustenis et al., 1998). In the case of Jupiter, too bright to be observed beyond $20 \mu \mathrm{m}$ in the grating mode, four lines were detected with the SWS FP mode between 28 and $45 \mu \mathrm{m}$ (Lellouch et al., 1997a,b).

Because of the cold trap of the tropopause, the observed water cannot come from tropospheric levels, and must be of external origin. It is likely that the observed water vapour comes from the sublimation of infalling icy particles; the water vapour diffuses downward and disappears due to condensation and/or chemical reactions. Surprisingly, the water flux inferred from the ISO water emission lines is in the same range for all objects $\left(10^{5}-10^{7} \mathrm{~cm}^{-2} \mathrm{~s}^{-1}\right)$. Water vapour is detected above pressure levels in the range $10 \mu \mathrm{bar}-10$ mbar, depending on the planet, with mean mixing ratios of about $10^{-9}$ for all planets and Titan. This similarity can provide a constraint on the possible source of water. Two major sources have been considered (Feuchtgruber et al., 1997; Lellouch et al., 1997b): the 'interplanetary source' which could be either micrometeoritic ice particles or larger objects like cometary nuclei, or the 'local' source which would include rings and icy satellites. The micrometeoritic source seems plausible, taking into account the interplanetary flux measured at $1 \mathrm{AU}$; the comet source looks more unlikely in view of the relatively low frequency of SL9-type events and the expected short lifetime of stratospheric water after such events. The local source would be expected to be highly variable from planet to planet. The fact that the measured $\mathrm{H}_{2} \mathrm{O}$ incoming fluxes are comparable, within a factor of 10 , for all planets and for Titan, seems to favor the interplanetary micrometeoritic source (Lellouch et al., 1997b).

The detection of $\mathrm{CO}_{2}$ on Jupiter, Saturn and 

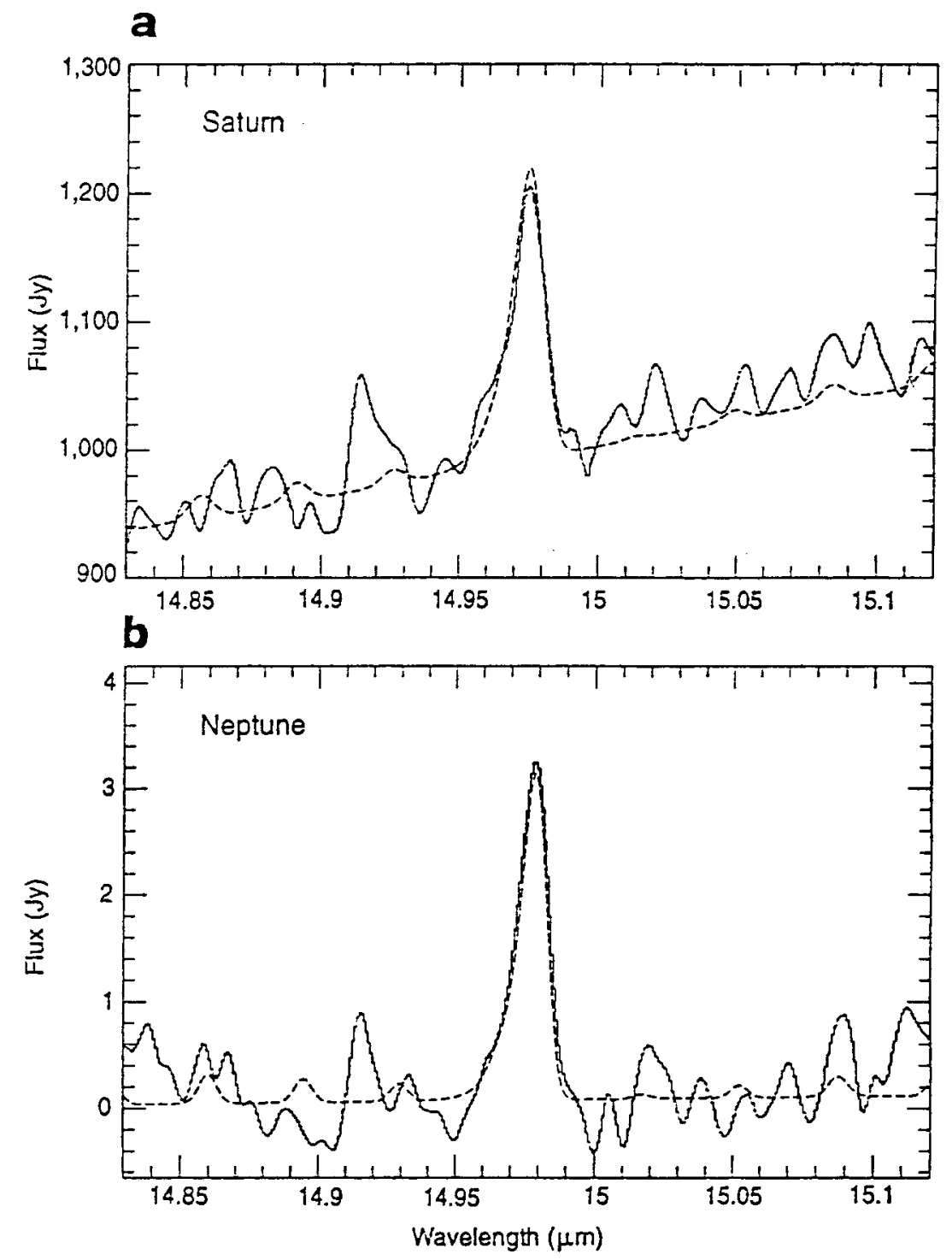

Fig. 11. Detection of $\mathrm{CO}_{2}$ on Saturn (de Graauw et al., 1997) and Neptune (Feuchtgruber et al., 1997). The figure is taken from Feuchtgruber et al. (1997).

Neptune (Fig. 11; see Section 7) is also to be discussed in the context of the external source of oxygen. Table 3 summarizes the abundances of oxygen compounds in the atmospheres of the giant planets and Titan. In the case of Neptune, $\mathrm{CO}_{2}$ is believed to be of stratospheric origin since any internal $\mathrm{CO}_{2}$ could not be transported through the cold trap of the tropopause. In addition $\mathrm{CO}$ is relatively abundant in Neptune's stratosphere $\left(1.2 \times 10^{-6}\right.$; Marten et al., 1993), so that $\mathrm{CO}_{2}$ could actually come from photochemical reactions involving $\mathrm{CO}$ and $\mathrm{OH}$. Alternately, $\mathrm{CO}_{2}$ could come, at least partly, from external icy particles. The lack of $\mathrm{CO}_{2}$ on Uranus' stratosphere might be explained by the absence of detectable amounts of $\mathrm{CO}$ in its stratosphere $\left(<3 \times 10^{-8}\right.$; Marten et al., 1993). This would favor the photochemical origin of $\mathrm{CO}_{2}$ on Neptune. In the case of Jupiter and Saturn, where stratospheric CO probably does not exceed a few $10^{-9}$, the origin of $\mathrm{CO}_{2}$ is uncertain: possible sources include vertical transport, external $\mathrm{CO}_{2}$ incoming flux or, in the case of Jupiter, the photochemical conversion of $\mathrm{H}_{2} \mathrm{O}$ to $\mathrm{CO}_{2}$ in the years following the SL9 collision (Moses, 1996). An additional source which requires further scrutiny is the reaction of externally delivered water with the planet's own hydrocarbons.

\section{Determination of the $\mathrm{D} / \mathrm{H}$ ratio}

Like all giant planets, Jupiter and Saturn are believed to have formed from the initial accretion of a central core, of about 10-15 terrestrial masses, fol- 
(a)

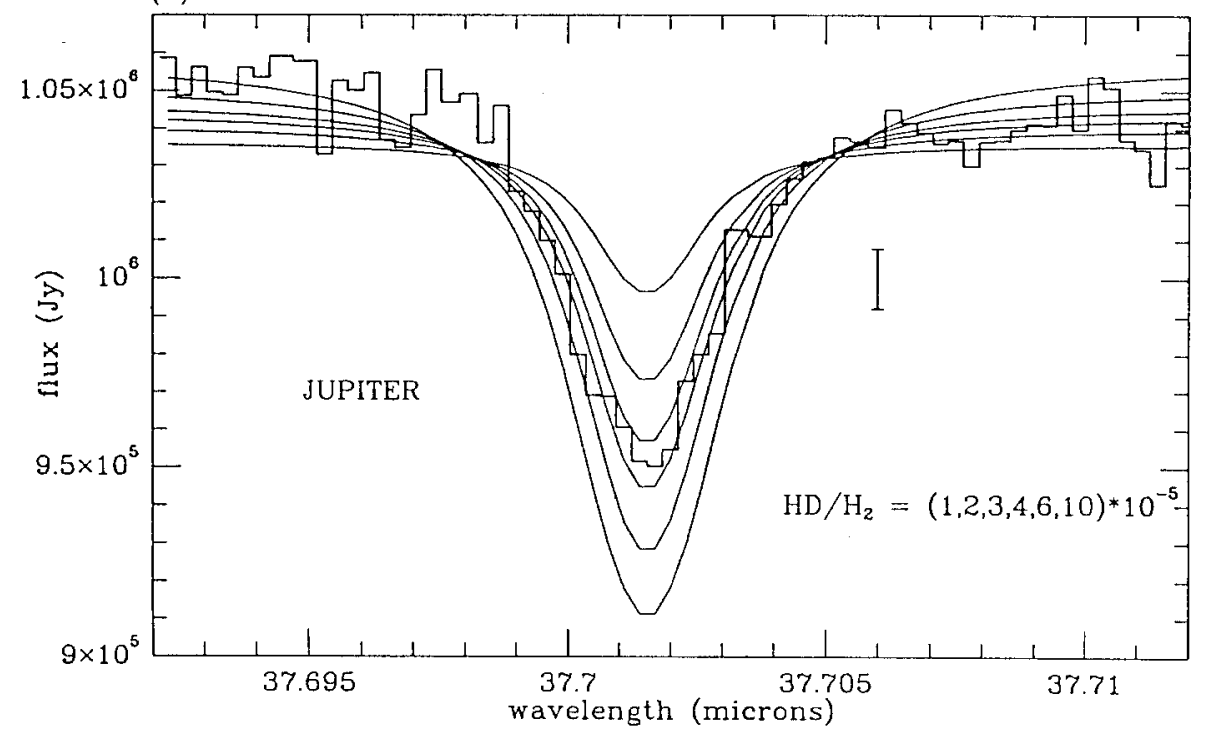

(b)

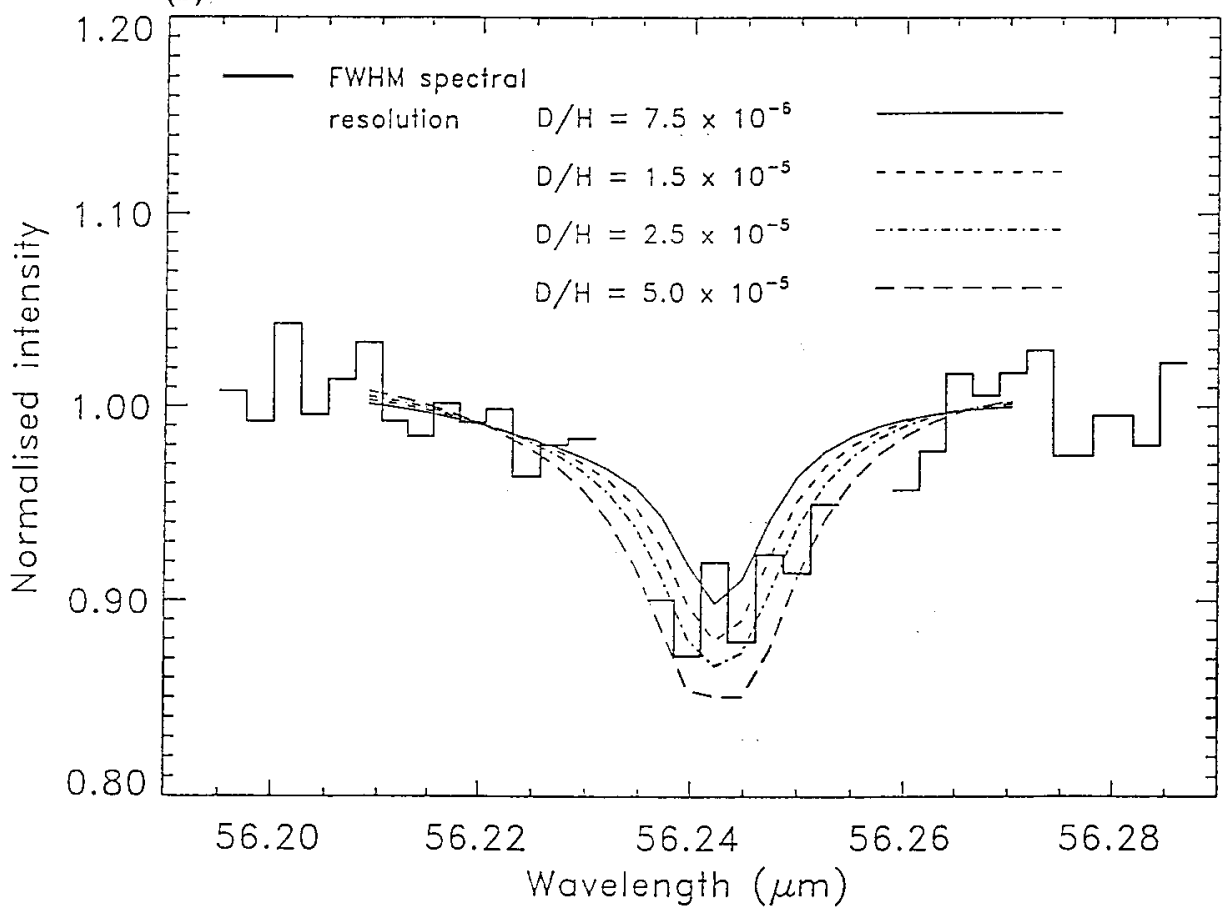

Fig. 12. (a) Detection of the $R(2)$ HD line on Jupiter with the SWS in the FP mode. The spectral resoluving power is 31000 . The figure is taken from Lellouch et al. (1997a; 1997b). (b) Detection of the $R(1)$ HD line on Saturn with the LWS in the FP mode. The resolving power is 8000. The figure is taken from Griffin et al. (1996). (c) Detection of the $R(2)$ HD on Uranus using the SWS grating. (d) Detection of the $R(2)$ HD line on Neptune using the SWS grating. Fig. 12(c) and (d) are taken from Feuchtgruber et al. (1999). 

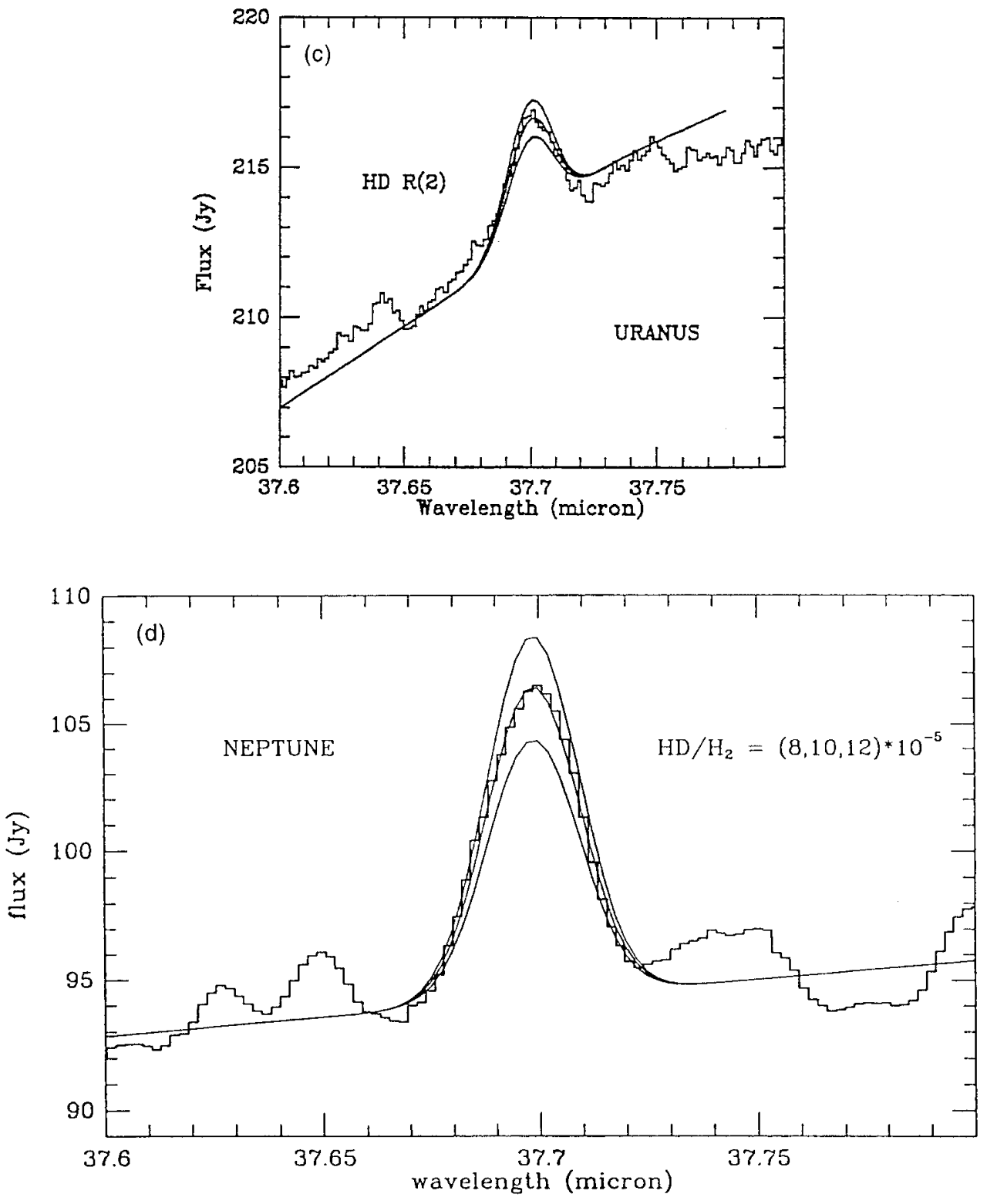

Fig. 12 (continued)

lowed by the gravitational collapse of the surrounding protosolar nebula. Because this central core represents only a small fraction of their total mass (about 3\% for Jupiter and $10 \%$ for Saturn), the $\mathrm{D} / \mathrm{H}$ ratio in their atmospheres is expected to be representative of its protosolar value. In contrast, in the case of Uranus and Neptune, their central cores must have accounted for more than $50 \%$ of their total mass. In these cores, accreted from icy planetesimals, the $\mathrm{D} / \mathrm{H}$ ratio is expected to have been enriched by isotopic exchange occurring in ion-molecule reactions (Irvine and Knacke, 1989) or molecule-molecule reactions (Lécluse et al., 1996); these reactions are known to lead to a deuterium enrichment in the ices $\left(\mathrm{H}_{2} \mathrm{O}, \mathrm{CH}_{4} \ldots\right)$ at low temperature, as observed in the interstellar medium (Irvine and Knacke, 1989). Such a deuterium enrichment is observed also in solar-system objects which accreted from ices, like comets and Titan (Owen et al., 1986; Eberhardt et al., 1995; Meier et al., 1998; Bockelée-Morvan et al., 1998). The $\mathrm{D} / \mathrm{H}$ value on Uranus and Neptune is thus expected to be enriched with respect to the Jupiter and Saturn value.

Previous measurements of $\mathrm{D} / \mathrm{H}$ in the giant planets were based on the study of either HD lines in the visible range, or $\mathrm{CH}_{3} \mathrm{D}$ transitions in the near or mid-infrared range. The first method suffers from uncertainties in the scattering processes involved in the line formation, while the second one is dependent 


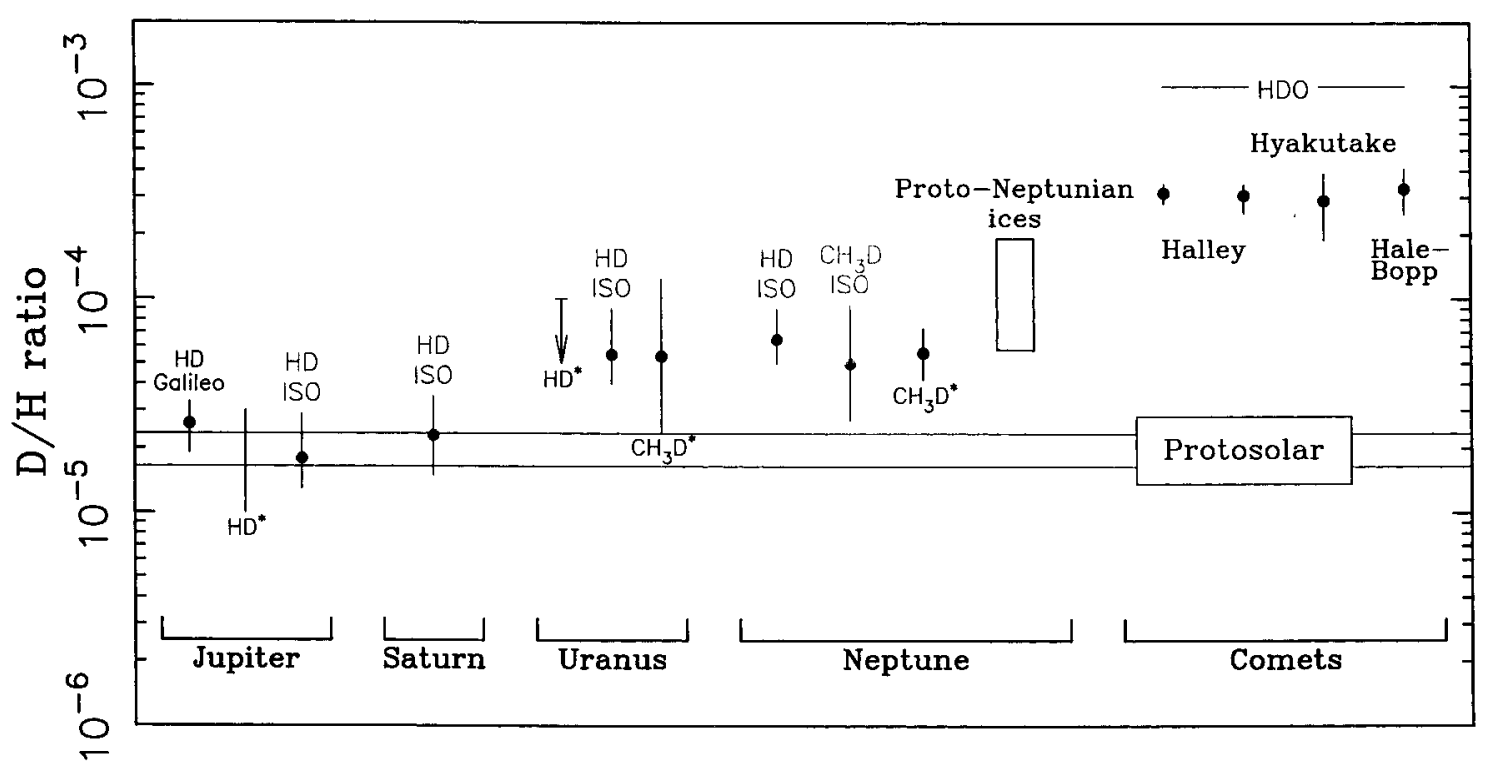

Fig. 13. D/H ratios in the Solar System. Asterisks indicate ground-based measurements, derived from Smith et al. (1989a) (HD, Jupiter), Smith et al. (1989b) (HD, Uranus and Neptune), Noll and Larson $\left(\mathrm{CH}_{3} \mathrm{D}\right.$, Saturn), de Bergh et al. (1986) $\left(\mathrm{CH}_{3} \mathrm{D}\right.$, Uranus), de Bergh et al. (1990) and Orton et al. (1992) $\left(\mathrm{CH}_{3} \mathrm{D}\right.$, Neptune). The Jupiter Galileo value is from Mahaffy et al. (1998). The figure is adapted from Bockelée-Morvan et al. (1998).

upon the determination of the fractionation factor $\mathrm{f}$, defined as $(\mathrm{D} / \mathrm{H})_{\mathrm{H} 2}=1 / f(\mathrm{D} / \mathrm{H})_{\mathrm{CH} 4}$. As a result, there is considerable uncertainty in these determinations (Gautier and Owen, 1989). In the case of Jupiter, a new in-situ measurement has been made recently by the Galileo probe (Mahaffy et al., 1998).

As first pointed out by Bézard et al. (1986), ISO offered the opportunity of obtaining a direct and homogeneous determination of $\mathrm{D} / \mathrm{H}$ in the four giant planets through the measurement of the infrared rotational HD lines. Observations of $R(0)$ at $112 \mu \mathrm{m}$, $R(1)$ at $56 \mu \mathrm{m}, R(2)$ at $37 \mu \mathrm{m}$ and $R(3)$ at $28 \mu \mathrm{m}$ have been performed using the LWS above $45 \mu \mathrm{m}$ and SWS below, both in the grating and in the Fabry-Pérot mode. Some of these data are still under reduction, and the following results are preliminary. For Jupiter, $\mathrm{D} / \mathrm{H}=1.8(+1.1,-0.5) \times 10^{-5}$ (Lellouch et al., 1997b) from the $R(2)$ line in the FP mode, Fig. 12a; for Saturn, $\mathrm{D} / \mathrm{H}=2.3(+1.2,-0 / 8) \times 10^{-5}$ (Griffin et al., 1996) from the $R(1)$ line in the FP mode, Fig. 12b); for Uranus, $\mathrm{D} / \mathrm{H}=5.5 \quad(+3.5, \quad-1.5) \times 10^{-5}$ (Feuchtgruber et al., 1999) from the $R(2)$ line in the grating mode, Fig. 12c; for Neptune, $\mathrm{D} / \mathrm{H}=6.5(+2.5$, $-1.5) \times 10^{-5}$ (Feuchtgruber et al., 1999) from $R(2)$ in the grating mode, Fig. 12d. These results are compared with other $\mathrm{D} / \mathrm{H}$ determinations in Fig. 13.

The ISO values agree well with previous determinations, as well as the most recent $\mathrm{D} / \mathrm{H}$ determination inferred from the Galileo probe (Mahaffy et al., 1998). Taking into account their error bars, the $\mathrm{D} / \mathrm{H}$ values in Jupiter and Saturn are also in agreement with the most recent determination of $\mathrm{D} / \mathrm{H}$ in the protosolar nebula, derived from ${ }^{3} \mathrm{He} /{ }^{4} \mathrm{He}$ in the solar wind $(3.0+/$ $-0.2 \times 10^{-5}$; Gautier and Morel, 1997). The Neptune measurement of $\mathrm{D} / \mathrm{H}$ from $\mathrm{HD}$ is in very good agreement with the ISO value inferred from the $\mathrm{CH}_{3} \mathrm{D}$ band at $8 \mu \mathrm{m}$ (Bézard et al., 1997), assuming a $f$ value of 1.6 for Neptune (Lécluse et al., 1996). Confirming previous ground-based measurements, the $\mathrm{D} / \mathrm{H}$ values in Uranus and Neptune are found to be higher than the protosolar value, as expected from the large size of their initial icy cores. Assuming now that the jovian $\mathrm{D} / \mathrm{H}$ value is representative of the protosolar nebula, an estimate of $\mathrm{D} / \mathrm{H}$ in the grains that formed the original cores can be inferred. In the case of Neptune, the result is $12(+6,-5) \times 10^{-5}$ (Lellouch et al., 1997a; 1997b); a similar value is found for Uranus. This result is a factor 2 greater than the Titan value (Coustenis et al., 1999) and about a factor 2 lower than the cometary value (Bockelée-Morvan et al., 1998). Because the deuterium exchange in the nebula depends on the temperature and pressure radial profiles and their evolution with time, constraints can be derived on evolutionary models of the solar nebula and on formation processes of distant solar-system objects.

\section{Conclusions and perspectives}

ISO observations of Jupiter and Saturn have provided an important contribution to our understanding of their chemical composition and thermal structure. Comparison with Voyager results has given information on temporal variations in their thermal profiles 
over a time scale of more than 15 years. In the near future, the simultaneous analysis of the Jupiter and Saturn infrared spectra over a very wide spectral range will be used to build a fully coherent atmospheric model of the two planets. The detection of many new stratospheric species should also allow a significant improvement of the photochemical models.

In the next decade, the FIRST submillimeter Earthorbiting astronomical mission is expected to provide another significant improvement to these studies. FIRST will be equipped with three focal instruments covering the $80 \mu \mathrm{m}-1 \mathrm{~mm}$ wavelength range with various spectroscopic capabilities. In particular, the heterodyne instrument (HIFI) should cover the whole submillimeter range up to a frequency of $1 \mathrm{THz}$ $(\lambda=334 \mu \mathrm{m})$ with a resolving power of about $10^{6}$ (Whyborn, 1997). This could allow the possible detection of new minor species including halides (Bézard et al., 1986; Encrenaz et al., 1995; Encrenaz, 1997). In addition, stratospheric emission lines of water should be easily detectable and will be used to retrieve the vertical distribution of $\mathrm{H}_{2} \mathrm{O}$; stratospheric $\mathrm{CO}$ and $\mathrm{HCN}$ will be searched for; $\mathrm{CH}_{4}$ rotational lines will be used for a retrieval of the stratospheric temperature and a precise determination of the $\mathrm{CH}_{4}$ mixing ratio.

\section{Acknowledgements}

ISO is an ESA project with instruments funded by ESA Member States (especially the PI countries: France, Germany, the Netherlands and the United Kingdom) and with the participation of ISAS and NASA. The SWS is a joint cooperation of the SRON and the MPE. SKA acknowledges support from NASA's Planetary Atmospheres Program.

\section{References}

Atreya, S.K., Donahue, T.M., Sandel, B.R., Broadfoot, A.L., Smith, G.R., 1979. Jovian upper atmosphere temperature measurement by the Voyager 1 UV Spectrometer. Geophys. Res. Lett. 6, 795798.

Atreya, S.K., Edgington, S.G., Encrenaz, Th, Feuchtgruber, H., 1999. ISO observations of $\mathrm{C} 2 \mathrm{H} 2$ on Uranus and $\mathrm{CH}_{3}$ on Saturn: implications for atmospheric vertical mixing in the Voyager and ISO epochs, and a call for relevant laboratory measurements ESA SP-427, in press.

Bézard, B., 1998. Detection of new hydrocarbons in the giant planets. Bull. Amer. Astron. Soc. 30, 1059-1059.

Bézard, B., Gautier, D., Marten, A., 1986. Detectability of HD and non-equilibrium species in the upper atmospheres of the giant planets from their submillimeter spectrum. Astron. Astrophys. $161,387-402$.

Bézard, B., Feuchtgruber, H., Moses, J.L., Encrenaz, Th, 1998. Detection of methyl radicals $\left(\mathrm{CH}_{3}\right)$ on Saturn. Astron. Astrophys. 334, L41-L44.

Bézard, B., Encrenaz, Th, Feuchtgruber, H., Lellouch, E., de
Graauw, Th, Griffin, M., Atreya, S.K., 1997. ISO-SWS observations of Neptune. Bull. Amer. Astron. Soc. 29, 993-993.

Bockelée-Morvan, D., et al., 1998. Deuterated Water in comet C/ 1996 B2 (Hyakutake) and its implications for the origin of comets. Icarus 133, 147-162.

Brooke, T.Y., Knacke, R.F., Encrenaz, Th, Drossart, P., Crisp, D., Feuchtgruber, H., 1998. Models of the ISO $3 \mu \mathrm{m}$ reflection spectrum of Jupiter. Icarus (in press).

Carlson, B.E., Lacis, A.A., Rossow, W.B., 1993. Tropospheric gas composition and cloud structure of the Jovian North Equatorial Band. J. Geophys. Res. 98, 5251-5290.

Carlson, B.E., Lacis, A.A., Rossow, W.B., 1994. Belt-zone variations in the Jovian cloud structure. J. Geophys. Res. 99, 14,623-14,658.

Carlson, R.W., et al., 1996. Near-infrared spectroscopy and spectral mapping of Jupiter and the galilean satellites: results from Galileo's initial orbit. Science 274, 385-388.

Cesarsky, C., et al., 1996. ISOCAM in flight. Astron. Astrophys. 315, L32-L37.

Clegg, P.E., et al., 1996. The ISO long-wavelength spectrometer. Astron. Astrophys. 315, L38-L42.

Courtin, R., Gautier, D., Marten, A., Bézard, B., Hanel, R., 1984. Astrophys. J. 287, 899.

Coustenis, A., Encrenaz, Th, Bézard, B., Bjoraker, G., Graner, G., Dang-Nhu, M., Arié, E., 1993. Modeling Titan's infrared spectrum for high-resolution space observations. Icarus 102, 240-260.

Coustenis, A., et al., 1998. Evidence for water vapour in Titan's atmosphere from ISO/SWS data. Astron. Astrophys. 336, L85-L89.

Coustenis, A. et al., 1998b. In preparation.

Davis, G.R., et al., 1996. ISO LWS measurements of the far-infrared spectrum of Saturn. Astron. Astrophys. 315, L393-L396.

de Graauw, Th, et al., 1996. Observing with the ISO short wavelength spectrometer. Astron. Astrophys. 315, L49-L54.

de Graauw, Th, et al., 1997. First results of ISO-SWS observations of Saturn: detection of $\mathrm{CO}_{2}, \mathrm{CH}_{3} \mathrm{C}_{2} \mathrm{H}, \mathrm{C}_{4} \mathrm{H}_{2}$ and tropospheric $\mathrm{H}_{2} \mathrm{O}$. Astron. Astrophys. 321, L13-L16.

de Pater, I., Massie, S.T., 1985. Models of the millimeter-centimeter spectra of the giant planets. Icarus 62, 143-171.

Drossart, P., 1998. Saturn tropospheric water measured with ISO/ SWS. Bull. Amer. Astron. Soc. 30, 1060-1060.

Drossart, P., Fouchet, T., Crovisier, J., Lellouch, E., Encrenaz, Th, Feuchtgruber, H., Champion, J-P., 1998. Fluorescence of methane in the atmosphere of Jupiter and Saturn from ISO-SWS observations at $3.3 \mu \mathrm{m}$. Bull. Amer. Astron. Soc. 30, 1063-1063.

Drossart, P., Fouchet, Th, Crovisier, J., Lellouch, E., Encrenaz, Th, Feuchtgruber, H., Champion, J. P., 1999. Fluorescence in the 3micron bands of methane on Jupiter and Saturn from ISO/SWS observations, ESA-SP 427, in press.

Eberhardt, P., Reber, M., Krankowsky, D., Hodges, R.R., 1995. The $\mathrm{D} / \mathrm{H}$ and ${ }^{16} \mathrm{O} /{ }^{18} \mathrm{O}$ ratios in water from Halley. Astron. Astrophys. 302, 301-316.

Encrenaz, Th, 1997. Observations of planetary and satellite atmospheres with FIRST. ESA-SP 401, 39-44.

Encrenaz, Th, Bézard, B., Crovisier, J., Coustenis, A., Lellouch, E., Gulkis, S., Atreya, S.K., 1995. Detectability of molecular species in planetary and satellite atmospheres from their rotational transitions. Plan. Space Sci. 43, 1485-1516.

Encrenaz, Th, et al., 1996a. First results of ISO-SWS observations of Jupiter. Astron. Astrophys. 315, L397-L400.

Encrenaz, Th, Serabyn, E., Weisstein, E.W., 1996b. Millimeter spectroscopy of Uranus and Neptune: constraints on $\mathrm{CO}$ and $\mathrm{PH}_{3}$ tropospheric abundances. Icarus 124, 616-624.

Encrenaz, Th, et al., 1997. The giant planets as seen by ISO. ESASP 419, 125-130.

Encrenaz, Th, et al., 1998. ISO observations of Uranus: the stratospheric distribution of $\mathrm{C}_{2} \mathrm{H}_{2}$ and the eddy diffusion coefficient. Astron. Astrophys. 333, L43-L46.

Feuchtgruber, H., Lellouch, E., de Graauw, Th, Bézard, B., 
Encrenaz, Th, Griffin, M., 1997. External supply of oxygen to the atmospheres of the giant planets. Nature 389, 159-162.

Feuchtgruber, H., Lellouch, E., Bézard, B., Encrenaz, Th, de Graauw, Th, Davis, G.R., 1999. First infrared detection of HD in the atmospheres of Uranus and Neptune: a new determination of the D/H ratio. Astron. Astrophys. 341, L17-L21.

Folkner, W.M., Woo, R., Nandi, S., 1998. Ammonia abundance in Jupiter's atmosphere derived from the attenuation of the Galileo probe's radio signal. J. Geophys. Res. 103, 22847-22855.

Fouchet, Th, Lellouch, E., Drossart, P., Encrenaz, Th, Bézard, B., Feuchtgruber, H., 1998. The Jupiter troposphere as seen with ISO/SWS. Bull. Amer. Astron. Soc. 30, 1061-1061.

Fouchet, Th, Lellouch, E., Encrenaz, Th, Drossart, P., Bézard, B., Feuchtgruber, H., de Graauw, Th, 1999. Observations of Jupiter with ISO/SWS: ammonia and hydrocarbons, ESA-SP 427, in press.

Gautier, D., Morel, P., 1997. A reestimate of the protosolar $\left({ }^{2} \mathrm{H} /{ }^{1} \mathrm{H}\right)_{\mathrm{p}}$ ratio from $\left({ }^{3} \mathrm{He} /{ }^{4} \mathrm{He}\right)_{\mathrm{sw}}$ solar wind measurements. Astron. Astrophys. 323, L9-L12.

Gautier, D., Owen, T., 1989. The composition of outer planet atmospheres. In: Atreya, S.K., et al. (Eds.), Origin and Evolution of Planetary and Satellite Atmospheres, pp. 487-512.

Gierasch, P., Conrath, B.J., Magalhaes, J.A., 1986. Zonal mean properties of Jupiter's upper troposphere from Voyager infrared observations. Icarus 67, 456-483.

Gladstone, G.R., Allen, M., Yung, Y.L., 1996. Hydrocarbon photochemistry in the upper atmosphere of Jupiter. Icarus 119, 1-52.

Gurwell, M.A., Muhleman, D.O., 1995. CO on Titan: evidence for a well-mixed atmosphere. Icarus 117, 375-382.

Irvine, W.M., Knacke, R.F., 1989. The chemistry of interstellar gas and grains. In: Atreya, S.K., et al. (Eds.), Origin and Evolution of Planetary and Satellite Atmospheres. Univ. of Arizona Press, pp. 3-34.

Irwin, P.G., et al., 1998. Cloud structure and atmospheric composition of Jupiter retrieved from Galileo NIMS real-time spectra. J. Geophys. Res. 103, 23,001-23,022.

Kerola, D.X., Larson, H.P., Tomasko, M.G., 1997. Analysis of the near-IR spectrum of Saturn: a comprehensive radiative transfer model in its middle and upper atmosphere. Icarus 127, 190-212.

Kessler, M.F., et al., 1996. The infrared Space Observatory (ISO) mission. Astron. Astrophys. 315, L27-L31.

Lam, H.A., Achilleos, N.A., Miller, S., Tennyson, J., Trafton, L.M., Geballe, T.R., Ballester, G.E., 1997a. A baseline spectroscopic study of the infrared aurorae of Jupiter. Icarus 127, 379-393.

Larson, H.P., Fink, U., Smith, H.A., Davis, D.S., 1980. The middleinfrared spectrum of Saturn: evidence for phosphine and upper limits to other trace atmospheric constituents. Astrophys. J. 240, 327-337.

Lécluse, C., Robert, F., Gautier, D., Guiraud, M., 1996. Deuterium enrichment in giant planets. Plan. Space Sci. 44, 1579-1592.

Lellouch, E., Feuchtgruber, H., de Graauw, Th, Bézard, B., Encrenaz, Th, Griffin, M.G., 1997a. $\mathrm{H}_{2} \mathrm{O}$ and $\mathrm{CO}_{2}$ in the upper atmospheres of the giant planets. Bull. Amer. Astron. Soc. 29, 992-992.

Lellouch, E., Feuchtgruber, H., de Graauw, T., Encrenaz, Th, Bézard, B., Griffin, M., 1997b. Deuterium and oxygen in the giant planets. ESA SP 419, 131-135.

Lellouch, E. et al., 1998. In preparation.

Lemke, D., et al., 1996. ISOPHOT: capabilities and performances. Astron. Astrophys. 315, L64-L70.

Lutz, B.L., de Bergh, C., Owen, T., 1983. Titan: discovery of carbon monoxide in its atmosphere. Science 220, 1374-1375.

Mahaffy, P.R., Donahue, T.M., Atreya, S.K., Owen, T.C., Niemann,
H.B., 1998. Galileo probe measurements of $\mathrm{D} / \mathrm{H}$ and ${ }^{3} \mathrm{He} /{ }^{4} \mathrm{He}$ in Jupiter's atmosphere. Space Science Rev. 84, 251-263.

Marten, A., et al., 1981. Study of the ammonia ice cloud layer in the equatorial region of Jupiter from the infrared interferometric experiment on Voyager. Icarus 46, 233-248.

Marten, A., Gautier, D., Tanguy, L., Lecacheux, A., Rosolen, C., Paubert, G., 1988. Abundance of carbon monoxide in the stratosphere of Titan from millimeter heterodyne observations. Icarus $76,233-248$.

Marten, A., et al., 1993. First observations of $\mathrm{CO}$ and $\mathrm{HCN}$ on Neptune and Uranus at millimeter wavelengths and their implications for atmospheric chemistry. Astrophys. J. 406, 285-297.

Meier, R., et al., 1998. A determination of the $\mathrm{HDO} / \mathrm{H}_{2} \mathrm{O}$ ratio in comet C/1995 O1 (Hale-Bopp). Science 279, 1707-1710.

Moses, J.L., 1996. SL9 impact chemistry: Long-term photochemical evolution. In: Noll, K.S., et al. (Eds.), The Collision of Comet Shoemaker-Levy 9 and Jupiter. Cambridge University Press, pp. 243-268.

Niemann, H.B., et al., 1996. The Galileo probe mass spectrometer: composition of Jupiter's atmosphere. Science 272, 846-849.

Niemann, H.B., et al., 1998. The composition of Jupiter's atmosphere as determined by the Galileo probe mass spectrometer. J. Geophys. Res. 103, 22,831-22,846.

Noll, K.S., Knacke, R.F., Geballe, R.T., Tokunaga, A.T., 1986. Detection of carbon monoxide in Saturn. Astrophys. J. 309, L91L94.

Noll, K.S., Knacke, R.F., Geballe, T.R., Tokunaga, A.T., 1988. The origin and vertical distribution of carbon monoxide on Jupiter. Astrophys. J. 324, 1210-1218.

Noll, K.S., Gilmore, D., Knacke, R.F., Womak, M., Griffith, C.A., Orton, G.S., 1997. Carbon Monoxide in Jupiter after Comet Shoemaker-Levy 9. Icarus 126, 324-335.

Orton, G.S., Appleby, J.F., Martonchik, J.V., 1982. The effect of ammonia ice on the outgoing thermal radiance from the atmosphere of Jupiter. Icarus 52, 94-116.

Owen, T., Lutz, B.L., de Bergh, C., 1986. Deuterium in the outer solar system: evidence for two distinct reservoirs. Nature 320, 244-246.

Romani, P., Bézard, B., Encrenaz, Th, Feuchtgruber, H., 1998. Detection of methyl radical in Neptune's atmosphere from ISO SWS observations. Bull. Amer. Astron. Soc. 30, 1060-1060.

Roos-Serote, M., et al., 1998. Analysis of Jupiter NEB hot spots in the 4-5 $\mu \mathrm{m}$ range from Galileo/NIMS observations: measurements of cloud opacity, water and ammonia. J. Geophys. Res. 103, 23,023-23,042.

Rosenqvist, J., Lellouch, E., Romani, P., Paubert, G., Encrenaz, Th, 1992. Millimeter-wave observations of Saturn, Uranus and Neptune: CO and HCN on Neptune. Astrophys. J. 392, L99L102.

Samuelson, R.E., et al., 1983. $\mathrm{CO}_{2}$ on Titan. J. Geophys. Res. 88, 8709-8715.

Waite, J.H., et al., 1997. Equatorial X-ray emissions: Implications for Jupiter's high exospheric temperatures. Science 276, 104-108.

West, R.A., Strobel, D.F., Tomasko, M.G., 1986. Clouds, aerosols and photochemistry in the Jovian atmosphere. Icarus 65, 161217.

Whyborn, N.D., 1997. The HIFI heterodyne instrument for FIRST: capabilities and performance. ESA-SP 401, 19-24.

Young, R.E., 1998. The Galileo Probe mission to Jupiter: Science overview. J. Geophys. Res. 103, 22,775-22,790.

Young, R.E., Smith, M.A., Sobeck, C.K., 1996. Galileo Probe: in situ observations of Jupiter's atmosphere. Science 272, 837-838.

Young, L.A., Yelle, R.V., Young, R., Seiff, A., Kirk, D.B., 1997. Gravity waves in Jupiter's thermosphere. Science 276, 108-111. 